\title{
Numerical Simulation and Investigation of System Parameters of Sonochemical Process
}

\author{
Sankar Chakma and Vijayanand S. Moholkar \\ Department of Chemical Engineering, Indian Institute of Technology Guwahati, Guwahati 781 039, Assam, India \\ Correspondence should be addressed to Sankar Chakma; sankar@iitg.ernet.in
}

Received 25 July 2013; Accepted 19 August 2013

Academic Editors: B.-Y. Cao, S. Tang, and G. Xiao

Copyright (C) 2013 S. Chakma and V. S. Moholkar. This is an open access article distributed under the Creative Commons Attribution License, which permits unrestricted use, distribution, and reproduction in any medium, provided the original work is properly cited.

\begin{abstract}
This paper presents the effects of various parameters that significantly affect the cavitation. In this study, three types of liquid mediums with different physicochemical properties were considered as the cavitation medium. The effects of various operating parameters such as temperature, pressure, initial bubble radius, dissolved gas content and so forth, were investigated in detail. The simulation results of cavitation bubble dynamics model showed a very interesting link among these parameters for production of oxidizing species. The formation of ${ }^{\circ} \mathrm{OH}$ radical and $\mathrm{H}_{2} \mathrm{O}_{2}$ is considered as the results of main effects of sonochemical process. Simulation results of radial motion of cavitation bubble dynamics revealed that bubble with small initial radius gives higher sonochemical effects. This is due to the bubble with small radius can undergo many acoustic cycles before reaching its critical radius when it collapses and produces higher temperature and pressure inside the bubble. On the other hand, due to the low surface tension and high vapor pressure, organic solvents are not suitable for sonochemical reactions.
\end{abstract}

\section{Introduction}

The sonochemistry concept is a well-established technique, and now it is considered as one of the most popular advanced oxidation processes. In the last few decades, sonochemical process became one of the most popular techniques for synthesis of catalysts as well as different types of materials [4-7], degradation of pollutants [8-12], synthesis of biodiesel $[13,14]$, and so forth. Numerous literatures on sonochemistry have already been published [15-18] which reported the various beneficial effects of sonochemistry. The principal phenomenon behind all of these effects is the cavitation. Cavitation is nothing but nucleation, growth, and implosive collapse of a bubble. Cavitation occurs through the formation of bubbles or cavities present in liquid medium. Each cavitating bubble contains gas or vapor or a mixture of gas-vapor. When bubble contains only gas, the expansion of bubble is mainly by diffusion, pressure reduction, or by rise in temperature. However, there are several parameters which are directly involved in transient cavitation. Transient cavitation is nothing but the growth of bubbles extensively over time scales of the order of the acoustic cycle and then undergoes an implosive/energetic collapse resulting in either fragmentation, decaying oscillation, or a repeat performance [19]. Cavitation can also be the result of the enlargement of cavities that are already present in bulk liquid. Sometimes cavitation bubbles are suspended/trapped in tinny cracks in the interface of solid and liquid. These cavitation bubbles grow and collapse in the medium based on the pressure variation inside the bubble. On the basis of pressure variation, cavitation can be categorized into four subsections: (1) hydrodynamic cavitation, (2) acoustic cavitation, (3) optic cavitation, and (4) particle cavitation [20]. Hydrodynamic cavitation is the result of pressure variation in the liquid medium due to the flow variation of liquid through the medium, while acoustic cavitation is due to the passing of acoustic waves in the liquid medium. Generally, acoustic cavitation occurs in the frequency range of $20 \mathrm{kHz}$ to $1 \mathrm{MHz}$, that is, high power low frequency [20]. In acoustic cavitation, very high temperature and pressure ( $5000 \mathrm{~K}$ and $\sim 500 \mathrm{bar})$ are produced inside the bubbles due to transient collapse of cavitation bubbles. The bubble collapse occurs within as small time as $50 \mathrm{~ns}$, and it is almost adiabatic. During the collapse of the bubble, many species are formed such as $\mathrm{H}_{2}, \mathrm{O}_{2}, \mathrm{H}_{2} \mathrm{O}_{2}$, 
$\mathrm{O}_{3},{ }^{\circ} \mathrm{OH},{ }^{\circ} \mathrm{H},{ }^{\circ} \mathrm{O}$, and $\mathrm{HO}_{2}{ }^{\circ}$. Among these species ${ }^{\circ} \mathrm{OH}$ radical is the most predominant radical species [21,22] having an oxidizing potential of $2.33 \mathrm{~V}[9,23]$. For greater details in cavitation concepts, we would like to refer the readers to see the state of art reviews by Xu et al. [4], Apfel [24], Gong and Hart [25], Suslick et al. [26], and Gogate and Pandit [27].

\section{Cavitation Bubble Dynamics Model}

In order to investigate the various effects of cavitation, we have considered a model for a single cavitation bubble to simulate the radial motion of cavitation bubble. Although the single bubble analysis for radial motion of cavitation bubble does not give the entire phenomenon of the sonochemical process, but it can give a qualitative physical insight into the mechanism. The resultant effect of sonochemical reaction is the collective oscillations and collapse of cavitation bubbles, with strong interaction between them. For simulation of radial motion, the single bubble model is the most popular model to present the effects of cavitation, namely, physical and chemical effect. The physical and chemical effects induced by ultrasound and cavitation bubbles in the system can be determined using diffusion limited ordinary differential equation (ODE) model. This model is basically based on the boundary layer approximation proposed by Toegel et al. [28]. This radial motion of cavitation bubble model is derived from the partial differential equation (PDE) model of Storey and Szeri [29], which showed that water vapor entrapment in the cavitation bubble is mainly a diffusion limited process and not the condensation limited process. The main components of the radial motion of cavitation bubble dynamics are: (1) Keller-Miksis equation for the radial motion of the bubble [30], (2) equation for the diffusive flux of water vapor and heat conduction through bubble wall. The overall diffusion coefficient in ternary mixture (e.g. $\mathrm{N}_{2}-\mathrm{O}_{2}-\mathrm{H}_{2} \mathrm{O}$ in case of air bubbles) or binary mixture (e.g., $\mathrm{N}_{2}-\mathrm{H}_{2} \mathrm{O}$ or $\mathrm{O}_{2}-\mathrm{H}_{2} \mathrm{O}$ or $\mathrm{Ar}-\mathrm{H}_{2} \mathrm{O}$ ) has been determined using Blanc's law [31], (3) equation for heat conduction through cavitation bubble wall, and (4) overall energy balance treating the cavitation bubble as an open system. The set of 4 ODEs are also given below.

(1) Radial motion of the cavitation bubble:

$$
\begin{aligned}
(1 & \left.-\frac{d R / d t}{c_{\mathrm{L}}}\right) R \frac{d^{2} R}{d t^{2}}+\frac{3}{2}\left(1-\frac{d R / d t}{3 c_{\mathrm{L}}}\right)\left(\frac{d R}{d t}\right)^{2} \\
= & \frac{1}{\rho_{\mathrm{L}}}\left(1+\frac{d R / d t}{c_{\mathrm{L}}}\right)\left(P_{i}-P_{t}\right) \\
& +\frac{R}{\rho_{\mathrm{L}} c_{\mathrm{L}}} \frac{d P_{i}}{d t}-4 \nu \frac{d R / d t}{R}-\frac{2 \sigma}{\rho_{\mathrm{L}} R} .
\end{aligned}
$$

Internal pressure in the bubble: $P_{i}=N_{\text {tot }}(t) k T /$ $\left[4 \pi\left(R^{3}(t)-h^{3}\right) / 3\right]$.

Pressure in bulk liquid medium: $P_{t}=P_{0}-P_{\mathrm{A}}$ $\sin (2 \pi f t)$.

(2) Diffusive flux of water molecules: $d N_{\mathrm{W}} / d t=4 \pi R^{2}$ $\left.D_{\mathrm{W}}\left(\partial C_{\mathrm{W}} / \partial r\right)\right|_{r=R} \approx 4 \pi R^{2} D_{\mathrm{W}}\left(\left(C_{\mathrm{W}, R}-C_{\mathrm{W}}\right) / l_{\text {diff }}\right)$.
Instantaneous diffusive penetration depth: $l_{\text {diff }}=\min \left(\sqrt{\left(R D_{\mathrm{w}}\right) /|d R / d t|}, R / \pi\right)$.

(3) Heat conduction across bubble wall: $d Q / d t=4 \pi R^{2} \lambda$ $\left.(\partial T / \partial r)\right|_{r=R} \approx 4 \pi R^{2} \lambda\left(\left(T_{0}-T\right) / l_{\mathrm{th}}\right)$.

Thermal diffusion length: $l_{\text {th }}=\min$ $(\sqrt{R \kappa /|d R / d t|}, R / \pi)$.

(4) Overall energy balance: $C_{V, \text { mix }} d T / d t=d Q / d t-P_{i} d V /$ $d t+\left(h_{\mathrm{W}}-U_{\mathrm{W}}\right) d N_{\mathrm{W}} / d t$.

Mixture heat capacity: $C_{V \text {,mix }}=\sum C_{V, i} N_{i}$ (where, $i=\mathrm{N}_{2} / \mathrm{O}_{2} / \mathrm{H}_{2} \mathrm{O}$ ).

Molecular properties of water: Enthalpy: $h_{\mathrm{w}}=$ $4 k T_{o}$.

Internal energy: $U_{\mathrm{W}}=N_{\mathrm{W}} k T\left(3+\sum_{i=1}^{3}\left(\left(\theta_{i} / T\right) /\right.\right.$ $\left.\left.\left(\exp \left(\theta_{i} / T\right)-1\right)\right)\right)$.

Heat capacity of various species $\left(i=\mathrm{N}_{2} / \mathrm{O}_{2} /\right.$ $\mathrm{H}_{2} \mathrm{O}$ ):

$$
C_{V, i}=N_{i} k\left(\frac{f_{i}}{2}+\sum\left(\frac{\left(\theta_{i} / T\right)^{2} \exp \left(\theta_{i} / T\right)}{\left(\exp \left(\theta_{i} / T\right)-1\right)^{2}}\right)\right) .
$$

The initial conditions of the ordinary differential equations are taken as: at $t=0, R=R_{o}, d R / d t=0, N_{\mathrm{w}}=$ $0, Q=0$, and $T=T_{o}$. Thermodynamic data for various species and physicochemical properties of various solvents, that is, cavitation medium, are given in Tables 1 and 2 . The thermal conductivity and diffusion coefficient (transport parameters for the heat and mass transfer) are estimated using Chapman-Enskog theory using Lennard-Jones 12-6 potential at the bulk temperature of the liquid medium [1$3,31]$. This model ignores the diffusion of gas across bubble interface, because the time scale for the diffusion of gases is much higher than the time scale of cavitation bubble model. The ODEs in the bubble dynamics model have been solved simultaneously using Runge-Kutta 4th-and 5th-order adaptive step size method [32]. Various parameters used in the numerical solution of radial motion of cavitation bubble dynamics and their numerical values are given in Tables 1 and 2. The other parameters are as follows: ultrasound frequency $(f)=20 \mathrm{kHz}$, ultrasound pressure amplitude $\left(P_{\mathrm{A}}\right)=150 \mathrm{kPa}$, initial bubble radius $\left(R_{o}\right)=5 \mu \mathrm{m}$, sound velocity in water $\left(c_{\mathrm{W}}\right)=1481 \mathrm{~m} / \mathrm{s}$, sound velocity in toluene $\left(c_{\mathrm{T}}\right)=1275 \mathrm{~m} / \mathrm{s}$, and sound velocity in $\mathrm{n}$-hexane $\left(c_{\mathrm{H}}\right)=1203 \mathrm{~m} / \mathrm{s}$. All these parameters remain unchanged unless otherwise stated.

Physical Effect of Ultrasound. Ultrasound propagates through the medium in the form of longitudinal wave with series of compression and rarefaction and causes rapid oscillatory motion of fluid elements called microstreaming. This motion gives rise to intense micromixing in the medium. The magnitude of the microstreaming velocity is given by $u=$ $P_{\mathrm{A}} / \rho c$. Substituting values of $P_{\mathrm{A}}$ as $1.5 \times 10^{5} \mathrm{~Pa}$ (or $1.5 \mathrm{bar}$ ), $\rho_{\mathrm{w}}=1000 \mathrm{~kg} / \mathrm{m}^{3}$, and $c_{\mathrm{w}}=1481 \mathrm{~m} / \mathrm{s}$ gives $u_{\mathrm{w}}=0.101 \mathrm{~m} / \mathrm{s}$.

Sonochemical Effect of Cavitation Bubbles. The numerical solution of bubble dynamics model predicts the temperature, 
TABLE 1: Thermodynamic data for various species (data taken from [1-3]).

\begin{tabular}{|c|c|c|c|c|}
\hline \multirow{2}{*}{ Species } & \multirow{2}{*}{$\begin{array}{l}\text { Degrees of freedom } \\
\text { (translational }+ \text { rotational) }\left(f_{i}\right)\end{array}$} & \multicolumn{2}{|c|}{ Lennard-Jones force constants } & \multirow{2}{*}{ Characteristic vibrational temperatures $\theta(\mathrm{K})$} \\
\hline & & $\sigma\left(10^{-10} \mathrm{~m}\right)$ & $\varepsilon / k(\mathrm{~K})$ & \\
\hline $\mathrm{N}_{2}$ & 5 & 3.68 & 92 & 3350 \\
\hline $\mathrm{O}_{2}$ & 5 & 3.43 & 113 & 2273 \\
\hline $\mathrm{Ar}$ & 3 & 3.42 & 124 & - \\
\hline $\mathrm{H}_{2} \mathrm{O}$ & 6 & 2.65 & 380 & $2295,5255,5400$ \\
\hline $\mathrm{C}_{6} \mathrm{H}_{12}$ & 6 & 5.75 & 386.4 & $1036,1932,1987,2104,4193$ \\
\hline $\mathrm{C}_{6} \mathrm{H}_{5}-\mathrm{CH}_{3}$ & 6 & 5.82 & 451 & $1004,1056,2112,2153,2326,4224,4375$ \\
\hline
\end{tabular}

TABle 2: Physicochemical properties of various solvents as cavitation medium.

\begin{tabular}{lccccc}
\hline Solvent & Boiling point $(\mathrm{K})$ & Density $\left(\mathrm{kg} / \mathrm{m}^{3}\right)$ & Viscosity $(\mathrm{Pa}-\mathrm{s})$ & Surface tension $(\mathrm{N} / \mathrm{m})$ & Vapor pressure $^{\#}(\mathrm{kPa})$ \\
\hline Water & 373 & 1000 & $1.0 \times 10^{-6}$ & 0.072 & 2.5 \\
Toluene & 384 & 867 & $6.8 \times 10^{-7}$ & 0.029 & 4.0 \\
n-Hexane & 341 & 658 & $5.0 \times 10^{-7}$ & 0.018 & 16.2 \\
\hline
\end{tabular}

\#: calculated using Antoine type correlations.

pressure, and the number of gas and solvent molecules in the bubble at transient collapse. At transient collapse, temperature and pressure reach extreme conditions, which result in dissociation of molecules to form various chemical species. To calculate the composition of the bubble at the time of collapse, we assume that thermodynamic equilibrium is attained [9]. The equilibrium mole fraction of different chemical species in the bubble at the peak conditions reached at transient collapse is estimated using Gibbs free-energy minimization technique [33]. The radial motion of cavitation bubbles generates intense convection in the medium through two phenomena.

(i) Microconvection [20]: $V_{\text {turb }}(r, t)=\left(R^{2} / r^{2}\right)(d R / d t)$.

(ii) Shock (or acoustic) waves $[34,35]: P_{\mathrm{AW}}(r, t)=\left(\rho_{\mathrm{L}} /\right.$ $4 \pi r)\left(d^{2} V_{b} / d t^{2}\right)=\rho_{\mathrm{L}}(R / r)\left[2(d R / d t)^{2}+R\left(d^{2} R / d t^{2}\right)\right]$,

where $V_{b}$ is the volume of the bubble. A representative value of $r$ is taken as $1 \mathrm{~mm}$. In bubble dynamic model, direct estimation of initial bubble radius is very difficult. Several phenomena such as rectified diffusion and fragmentation of the bubble cause continuous change in this parameter. In a multibubble system, a large variation in this parameter may be expected. In order to investigate the influence of this parameter, two numerical values for this parameter, namely, 5 and $10 \mu \mathrm{m}$, are selected for this present study. The equilibrium composition of the bubble contents was determined using the FactSage online software [36], which is based on the free-energy minimization algorithm same as proposed by Eriksson [33].

\section{Numerical Solution of Mathematical Model}

The simulation results of radial motion of cavitation bubble dynamics are depicted in Figures 1, 2, 3, 4, and 5 and Tables $3,4,5,6$, and 7 . Tables $3-7$ present the temperature $\left(T_{\max }\right)$ and pressure $\left(P_{\max }\right)$ peaks reached at the moment of transient collapse of cavitation bubble, the number of water molecules in the bubble at collapse, and the equilibrium composition of the various species resulting from dissociation of entrapped molecules in the bubble when the temperature and pressure reached to its extreme conditions during transient collapse of cavitation bubbles.

3.1. Initial Bubble Size in the Liquid Medium. Bubbles with different initial radius present in the liquid medium play an important role in cavitation. Kumar and Moholkar [37] have reported that the smaller bubble has higher Laplace pressure, which results in higher expansion and more intense collapse during the transient collapse. In this present study, a single bubble model with different initial radius has been chosen to present the effects of bubble radius in sonochemical process. From Table 3 , it could be seen that the ${ }^{\circ} \mathrm{OH}$ radical formation during transient collapse of cavitation bubble is higher with the initial bubble radius of $5 \mu \mathrm{m}$ followed by $25 \mu \mathrm{m}$. This is due to the bubble with small bubble radius can undergo many acoustic cycles before reaching its critical radius when it collapses, and as a result the highest temperature peak is reached at the moment of transient collapse of the cavitation bubble with $5 \mu \mathrm{m}$ radius bubble as shown in Figure 1 and Table 3.

3.2. Static Pressure of the System. As stated earlier in the previous section, the cavitation is nothing but the nucleation, growth, and implosive collapse of bubbles, but the growth/expansion of the bubble depends on the system's static pressure. So, when the bubble contains vapor, cavitation may occur due to reduced static pressure sufficiently at constant temperature. To investigate the effects of pressure, five different static pressures ranging from 100-300 kPa have been chosen. The results showed that as the static pressure increases the radical formation decreases drastically; even it becomes zero at higher ambient static pressure. This is due to at elevated static pressure, the sonochemical effects get eliminated which directly affects the generation of radical formation, provided the applied pressure must be greater than or equal to the acoustic pressure amplitude $\left(P_{o} \geq P_{\mathrm{AW}}\right)$ $[9,38]$. The highest ${ }^{\circ} \mathrm{OH}$ radical production was seen at nearly 

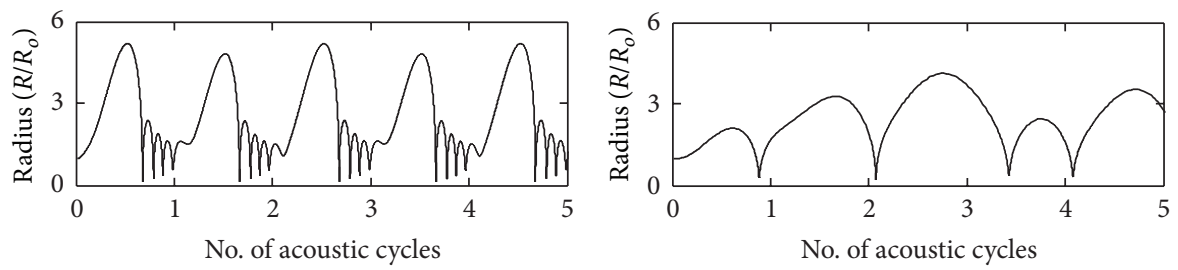

(a)
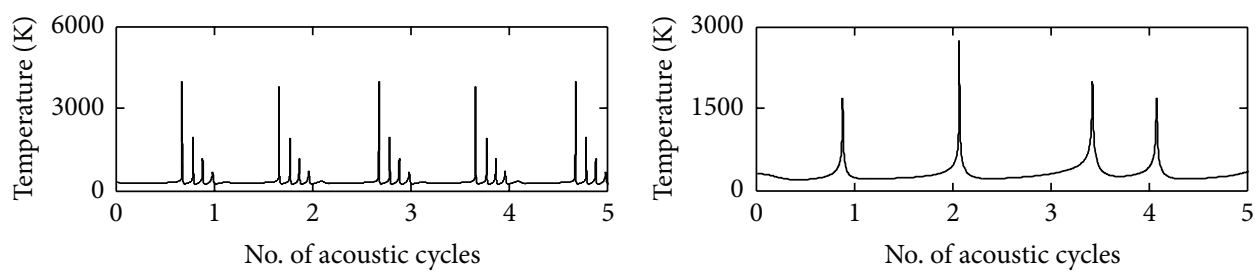

(b)
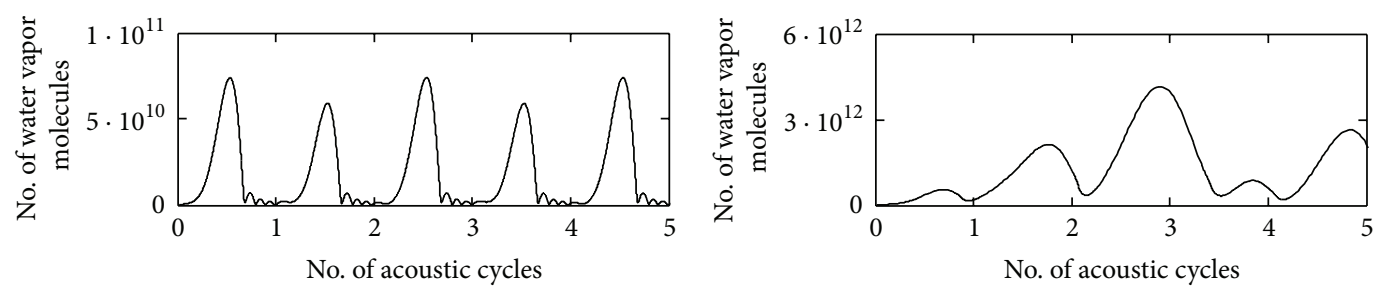

(c)
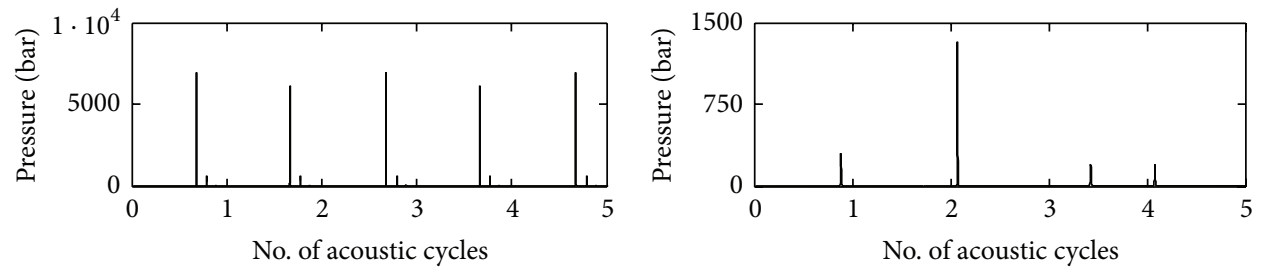

(d)
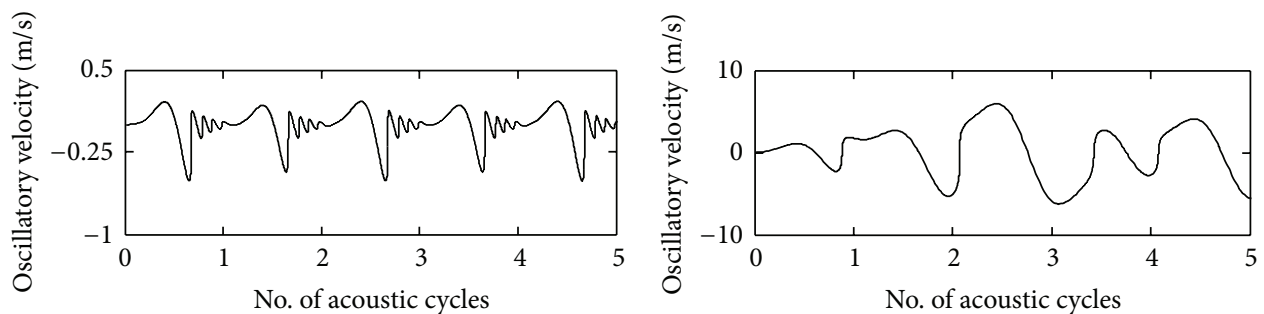

(e)
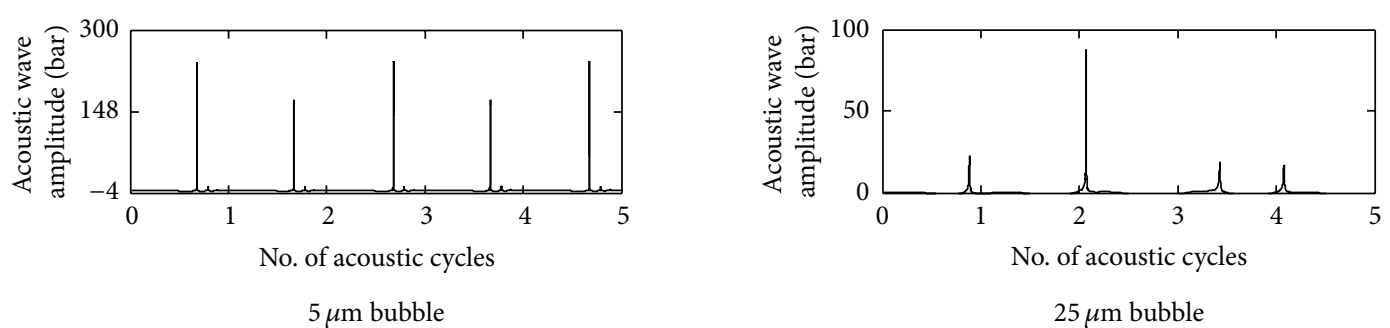

$25 \mu \mathrm{m}$ bubble

(f)

Figure 1: Simulations of radial motion of 5 and 25 micron air bubble in water. $f=20 \mathrm{kHz} ; P_{\mathrm{A}}=150 \mathrm{kPa}$; and $P_{o}=100 \mathrm{kPa}$. Time history of (a) radius of the bubble; (b) temperature inside the bubble; (c) water vapor evaporation in the bubble; (d) pressure inside the bubble; (e) microturbulence generated by the bubble; and (f) acoustic waves emitted by the bubble. 

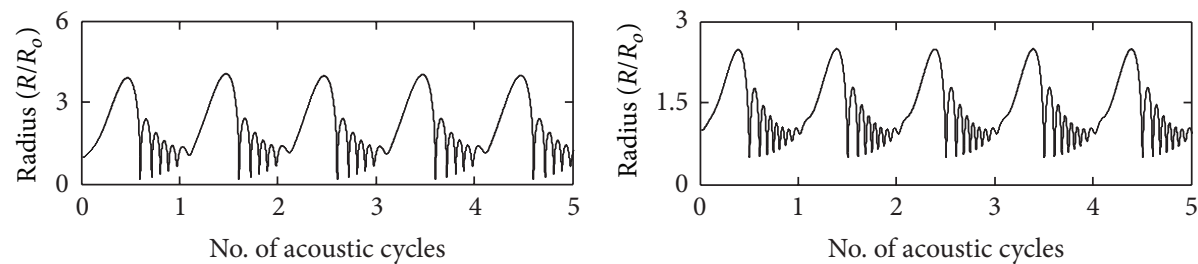

(a)
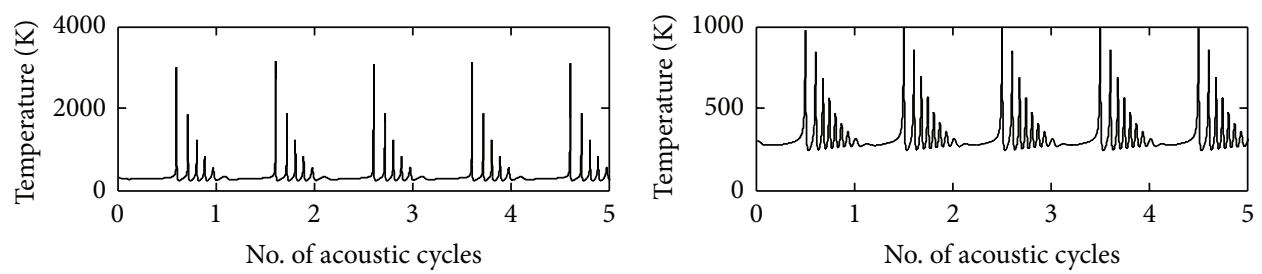

(b)
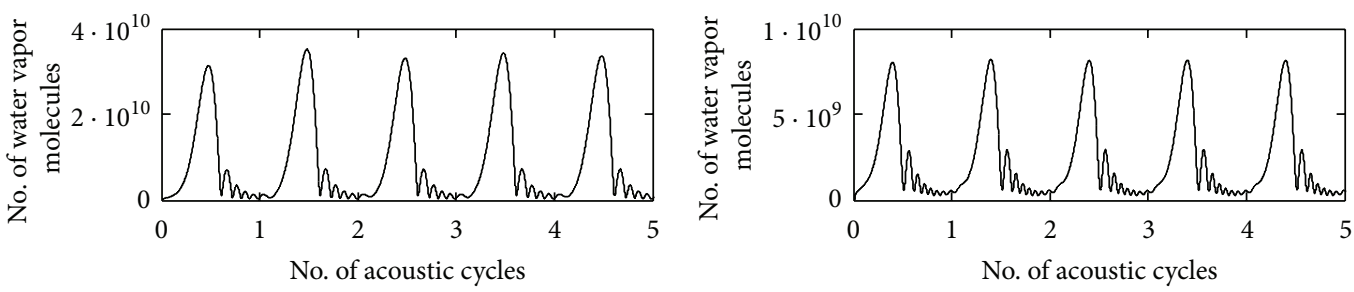

(c)
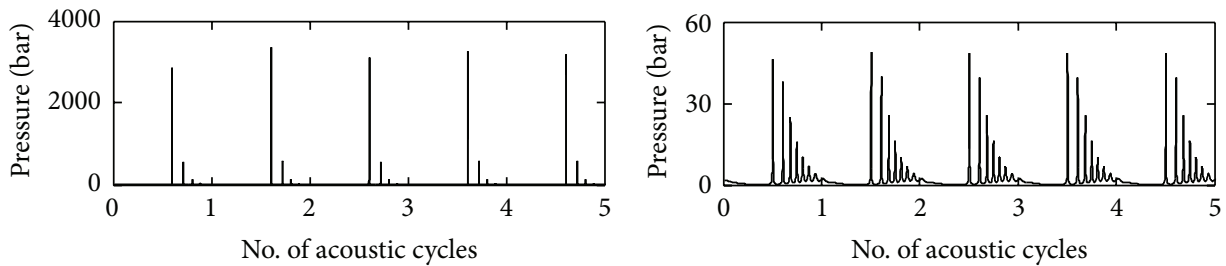

(d)
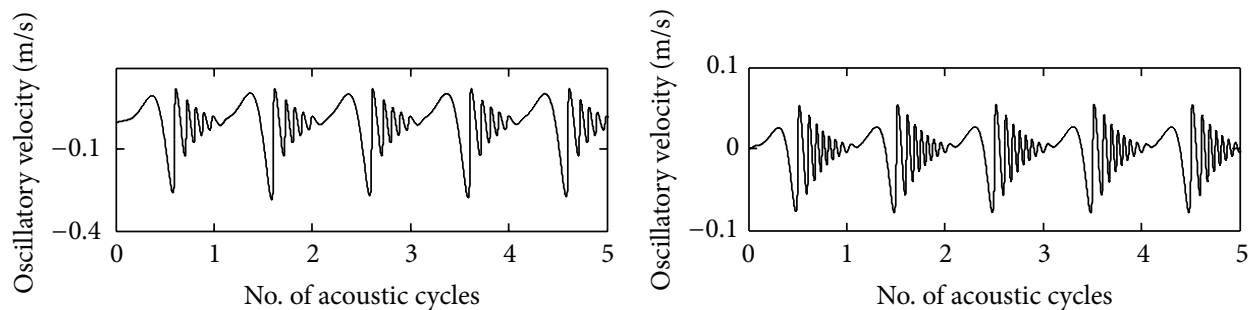

(e)
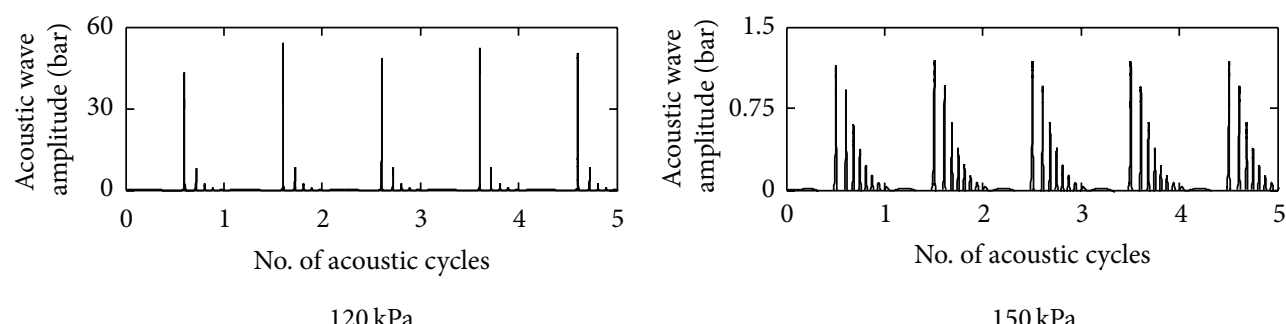

(f)

Figure 2: Simulations of radial motion of 5 micron air bubble in water at $120 \mathrm{kPa}$ and $150 \mathrm{kPa} . f=20 \mathrm{kHz} ; P_{\mathrm{A}}=150 \mathrm{kPa}$; and $R_{o}=5 \mu \mathrm{m}$. Time history of (a) radius of the bubble; (b) temperature inside the bubble; (c) water vapor evaporation in the bubble; (d) pressure inside the bubble; (e) microturbulence generated by the bubble; and (f) acoustic waves emitted by the bubble. 

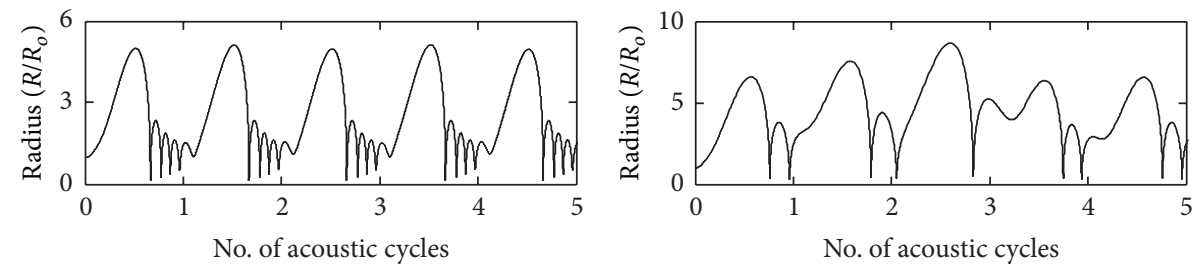

(a)
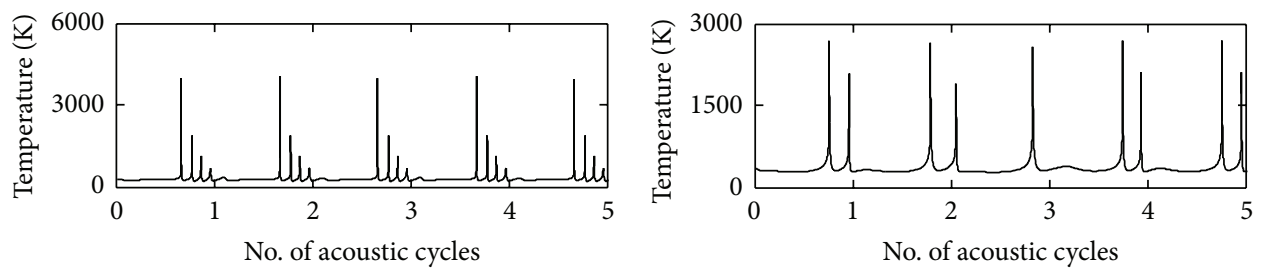

(b)
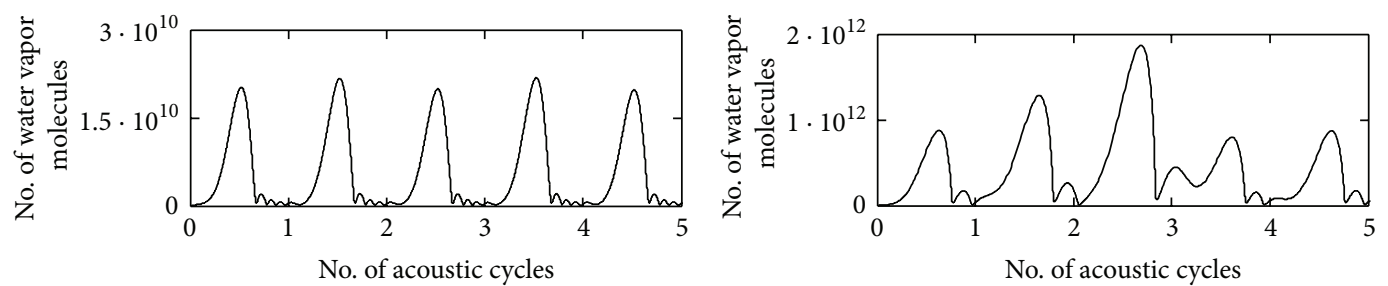

(c)
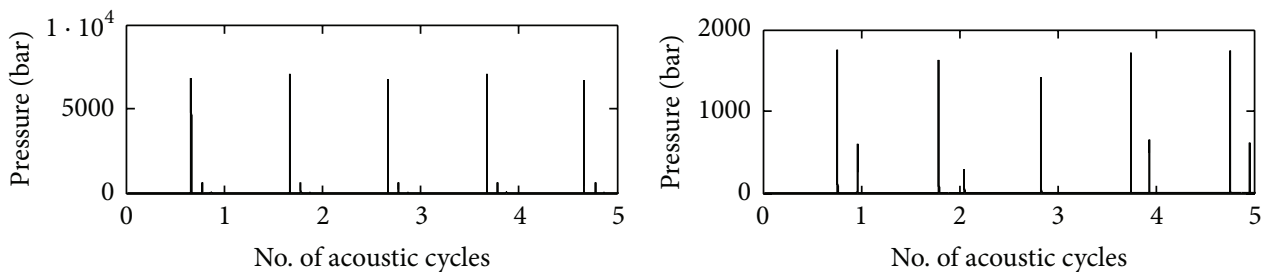

(d)
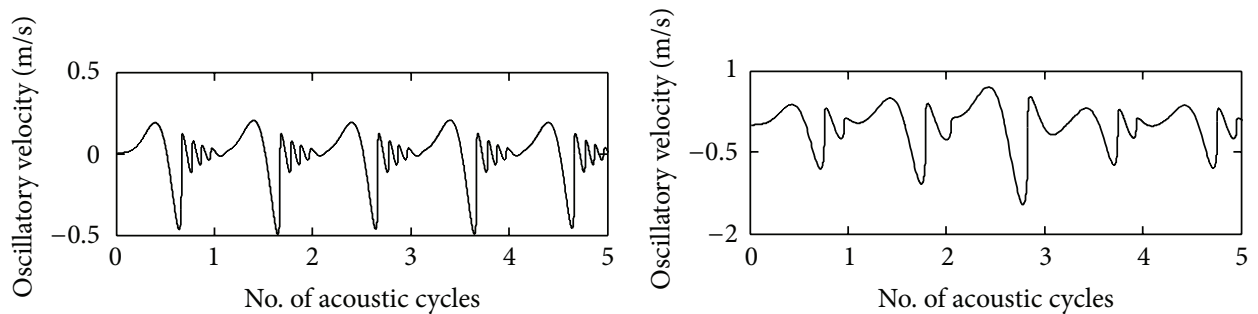

(e)

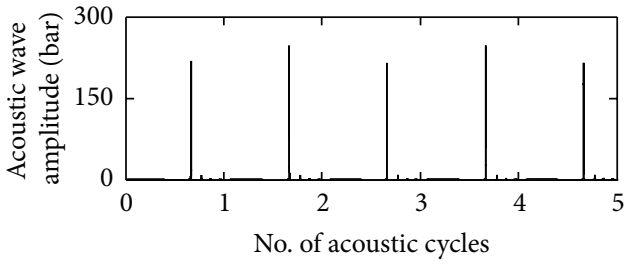

$283 \mathrm{~K}$

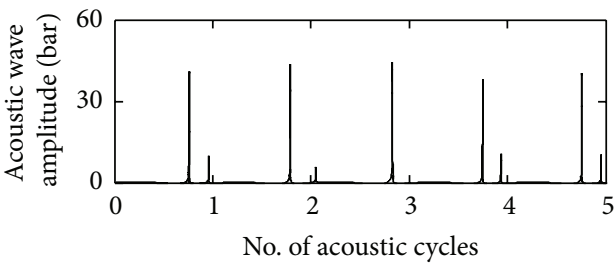

$343 \mathrm{~K}$

(f)

Figure 3: Simulations of radial motion of 5 micron air bubble in water at $283 \mathrm{~K}$ and $343 \mathrm{~K} . f=20 \mathrm{kHz} ; P_{\mathrm{A}}=150 \mathrm{kPa}$; and $P_{o}=100 \mathrm{kPa}$. Time history of (a) radius of the bubble; (b) temperature inside the bubble; (c) water vapor evaporation in the bubble; (d) pressure inside the bubble; (e) microturbulence generated by the bubble; and (f) acoustic waves emitted by the bubble. 

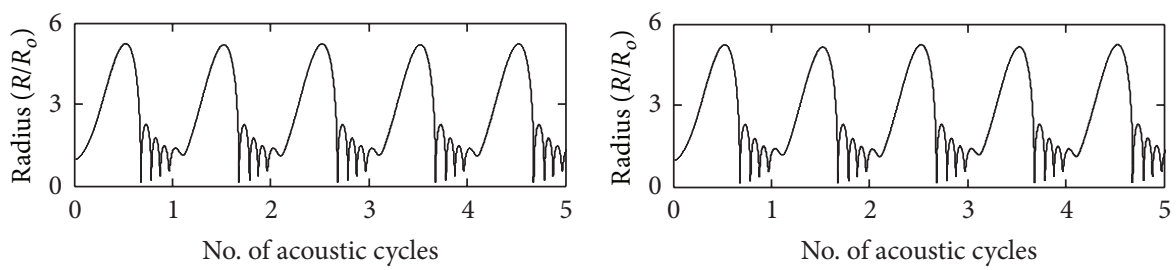

(a)
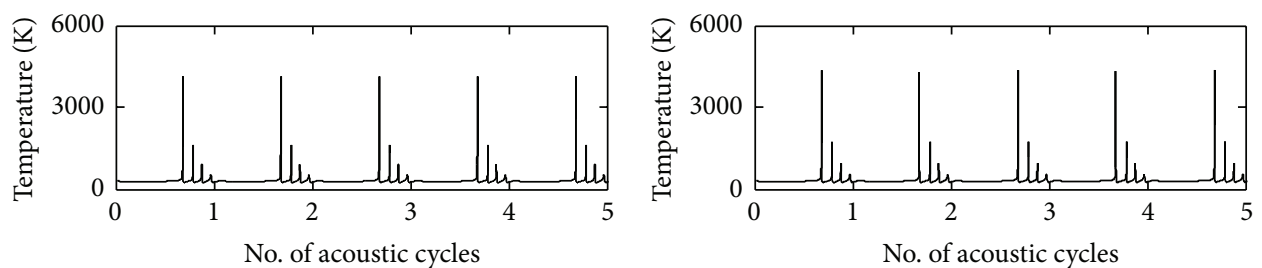

(b)
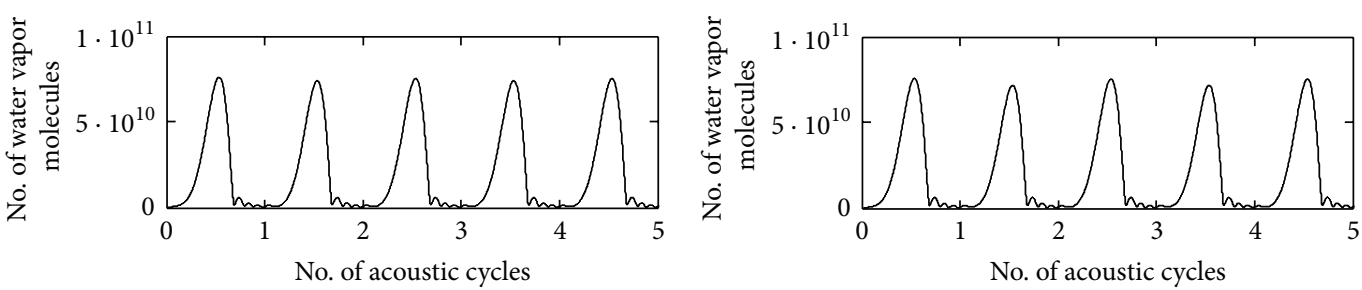

(c)
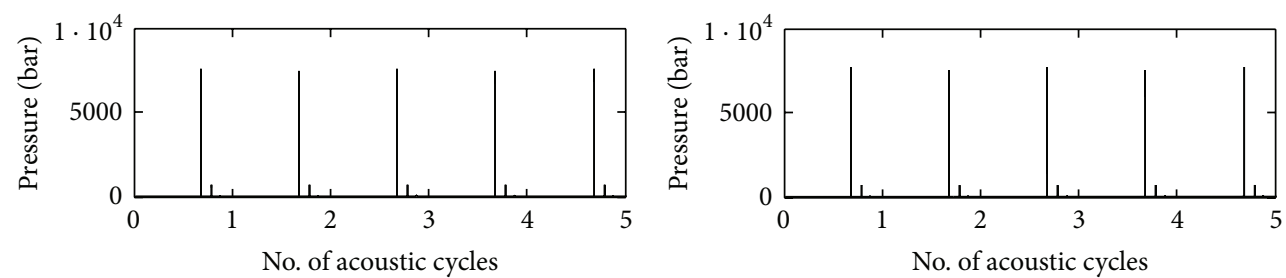

(d)
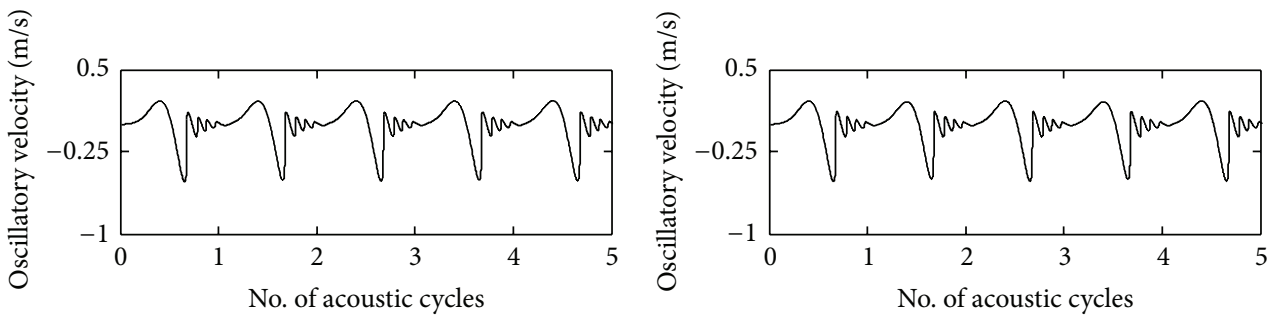

(e)

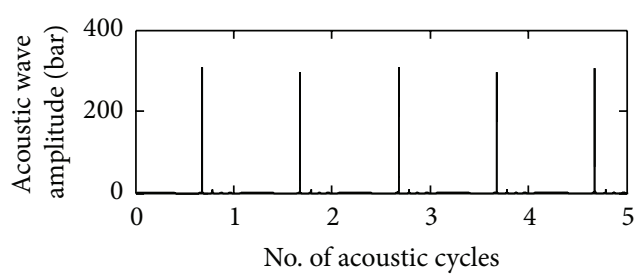

Oxygen bubble

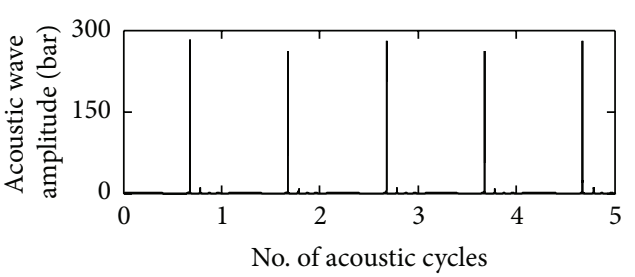

Nitrogen bubble

(f)

Figure 4: Simulations of radial motion of 5 micron air bubble in water with $\mathrm{O}_{2}$ bubble and $\mathrm{N}_{2}$ bubble. $f=20 \mathrm{kHz} ; P_{\mathrm{A}}=150 \mathrm{kPa}$; and $P_{o}=100 \mathrm{kPa}$. Time history of (a) radius of the bubble; (b) temperature inside the bubble; (c) water vapor evaporation in the bubble; (d) pressure inside the bubble; (e) microturbulence generated by the bubble; and (f) acoustic waves emitted by the bubble. 

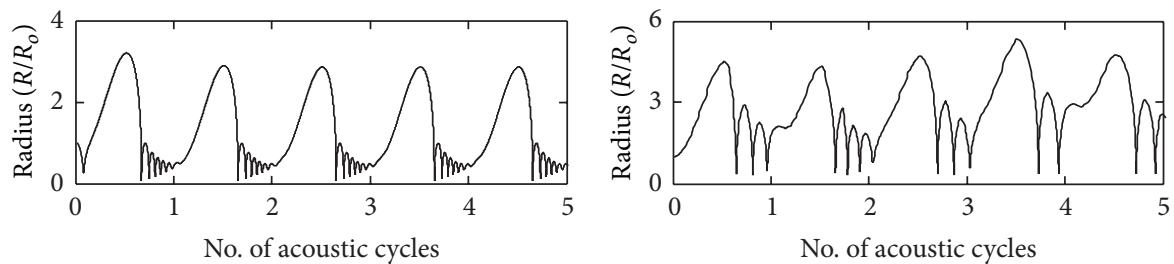

(a)
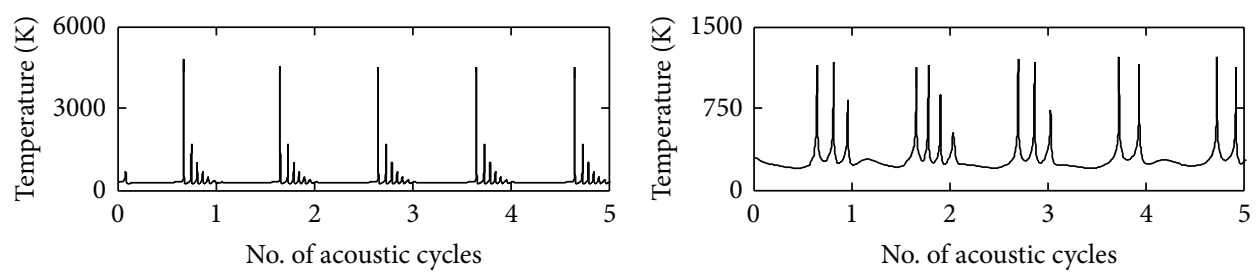

(b)
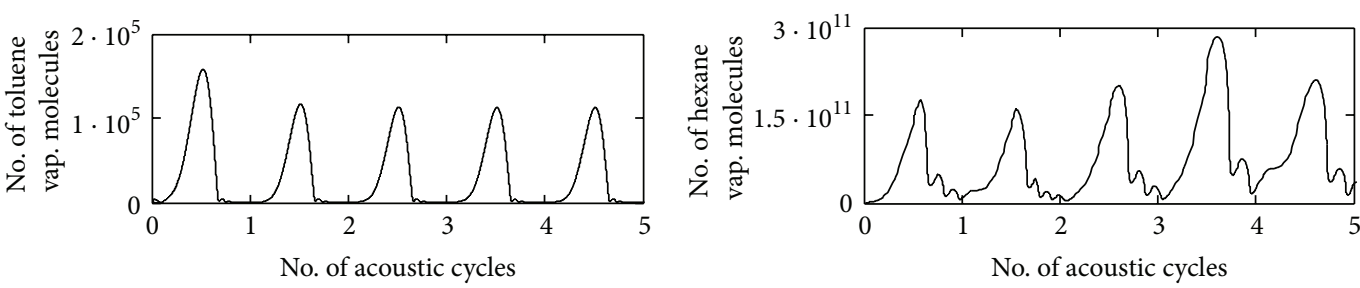

(c)
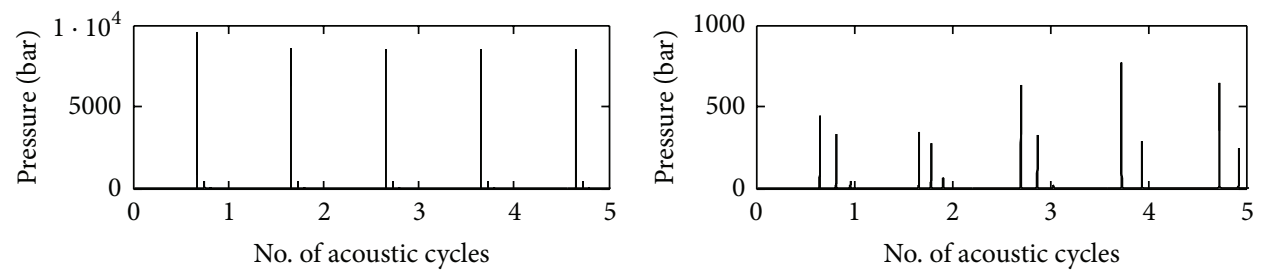

(d)
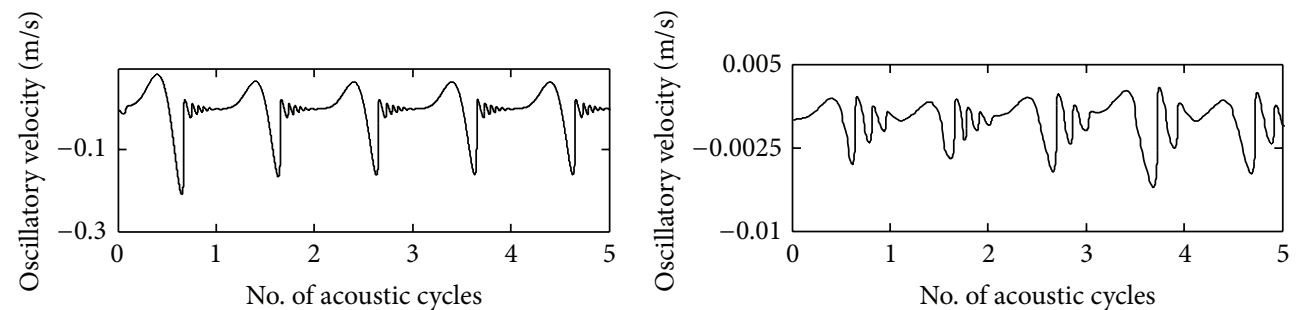

(e)
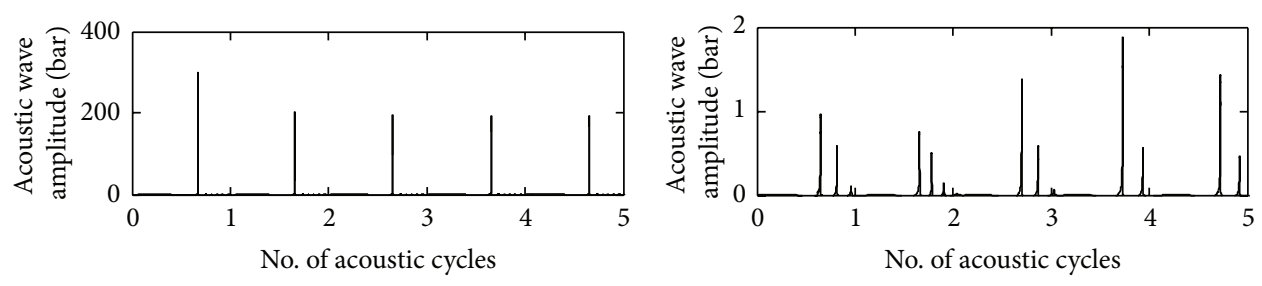

Toluene

n-hexane

(f)

FIgURE 5: Simulations of radial motion of 5 micron air bubble in toluene and $\mathrm{n}$-hexane as cavitation medium. $f=35 \mathrm{kHz} ; P_{\mathrm{A}}=150 \mathrm{kPa}$; and $P_{o}=100 \mathrm{kPa}$. Time history of (a) radius of the bubble; (b) temperature inside the bubble; (c) water vapor evaporation in the bubble; (d) pressure inside the bubble; (e) microturbulence generated by the bubble; and (f) acoustic waves emitted by the bubble. 
TABLE 3: Simulation summary of initial bubble size $\left(R_{o}\right)$ dependent sonochemical process.

\begin{tabular}{|c|c|c|c|c|c|}
\hline & \multicolumn{5}{|c|}{ Conditions at the first collapse of the bubble } \\
\hline & $R_{o}=5 \mu \mathrm{m}$ & $R_{o}=25 \mu \mathrm{m}$ & $R_{o}=50 \mu \mathrm{m}$ & $R_{o}=100 \mu \mathrm{m}$ & $R_{o}=200 \mu \mathrm{m}$ \\
\hline & $T_{\max }=3999 \mathrm{~K}$ & $T_{\max }=1688 \mathrm{~K}$ & $T_{\max }=778.5 \mathrm{~K}$ & $T_{\max }=409 \mathrm{~K}$ & $T_{\max }=329.9 \mathrm{~K}$ \\
\hline & $P_{\max }=696.7 \mathrm{MPa}$ & $P_{\max }=30.57 \mathrm{MPa}$ & $P_{\max }=2.56 \mathrm{MPa}$ & $P_{\max }=288 \mathrm{kPa}$ & $P_{\max }=136 \mathrm{kPa}$ \\
\hline & $V_{\text {turb }}=0.36 \mathrm{~m} / \mathrm{s}$ & $V_{\text {turb }}=6.11 \mathrm{~m} / \mathrm{s}$ & $V_{\text {turb }}=6.2 \mathrm{~m} / \mathrm{s}$ & $V_{\text {turb }}=7.95 \mathrm{~m} / \mathrm{s}$ & $V_{\text {turb }}=11.2 \mathrm{~m} / \mathrm{s}$ \\
\hline & $P_{\mathrm{AW}}=24.04 \mathrm{MPa}$ & $P_{\mathrm{AW}}=8.80 \mathrm{MPa}$ & $P_{\mathrm{AW}}=0.63 \mathrm{MPa}$ & $P_{\mathrm{AW}}=0.27 \mathrm{MPa}$ & $P_{\mathrm{AW}}=0.35 \mathrm{kPa}$ \\
\hline & $N_{\mathrm{N}_{2}}=1.28 \times 10^{10}$ & $N_{\mathrm{N}_{2}}=1.32 \times 10^{12}$ & $N_{\mathrm{N}_{2}}=1.03 \times 10^{13}$ & $N_{\mathrm{N}_{2}}=8.11 \times 10^{13}$ & $N_{\mathrm{N}_{2}}=6.44 \times 10^{14}$ \\
\hline & $N_{\mathrm{O}_{2}}=3.41 \times 10^{9}$ & $N_{\mathrm{O}_{2}}=3.51 \times 10^{11}$ & $N_{\mathrm{O}_{2}}=2.73 \times 10^{12}$ & $N_{\mathrm{O}_{2}}=2.16 \times 10^{13}$ & $N_{\mathrm{O}_{2}}=1.71 \times 10^{14}$ \\
\hline & $N_{\mathrm{W}}=2.91 \times 10^{9}$ & $N_{\mathrm{W}}=2.5 \times 10^{11}$ & $N_{\mathrm{W}}=9.08 \times 10^{11}$ & $N_{\mathrm{W}}=2.98 \times 10^{12}$ & $N_{\mathrm{W}}=1.15 \times 10^{13}$ \\
\hline \multirow{2}{*}{ Species } & \multicolumn{5}{|c|}{ Equilibrium composition of species in the bubble at collapse } \\
\hline & $5 \mu \mathrm{m}$ & $25 \mu \mathrm{m}$ & $50 \mu \mathrm{m}$ & $100 \mu \mathrm{m}$ & $200 \mu \mathrm{m}$ \\
\hline $\mathrm{N}_{2}$ & $6.26 \times 10^{-1}$ & $6.86 \times 10^{-1}$ & $7.38 \times 10^{-1}$ & $7.68 \times 10^{-1}$ & $7.79 \times 10^{-1}$ \\
\hline $\mathrm{O}_{2}$ & $1.28 \times 10^{-1}$ & $1.82 \times 10^{-1}$ & $1.96 \times 10^{-1}$ & $2.04 \times 10^{-1}$ & $2.07 \times 10^{-1}$ \\
\hline $\mathrm{H}_{2} \mathrm{O}$ & $1.41 \times 10^{-2}$ & $1.30 \times 10^{-1}$ & $6.50 \times 10^{-2}$ & $2.80 \times 10^{-2}$ & $1.40 \times 10^{-2}$ \\
\hline $\mathrm{N}$ & $1.56 \times 10^{-5}$ & - & - & - & - \\
\hline $\mathrm{O}$ & $5.95 \times 10^{-3}$ & - & - & - & - \\
\hline $\mathrm{H}$ & $2.83 \times 10^{-4}$ & - & - & - & - \\
\hline $\mathrm{O}_{3}$ & $1.70 \times 10^{-5}$ & - & - & - & - \\
\hline $\mathrm{H}_{2}$ & $2.53 \times 10^{-4}$ & - & - & - & - \\
\hline $\mathrm{OH}$ & $9.51 \times 10^{-3}$ & $9.03 \times 10^{-5}$ & - & - & - \\
\hline $\mathrm{HO}_{2}$ & $5.59 \times 10^{-4}$ & $5.81 \times 10^{-6}$ & - & - & - \\
\hline $\mathrm{H}_{2} \mathrm{O}_{2}$ & $2.00 \times 10^{-5}$ & - & - & - & - \\
\hline NO & $8.47 \times 10^{-2}$ & $2.58 \times 10^{-3}$ & $1.49 \times 10^{-6}$ & - & - \\
\hline $\mathrm{NO}_{2}$ & $1.70 \times 10^{-3}$ & $1.27 \times 10^{-4}$ & $2.84 \times 10^{-6}$ & - & - \\
\hline $\mathrm{N}_{2} \mathrm{O}$ & $3.61 \times 10^{-4}$ & $2.18 \times 10^{-6}$ & - & - & - \\
\hline $\mathrm{NH}$ & $1.70 \times 10^{-6}$ & - & - & - & - \\
\hline $\mathrm{HNO}$ & $5.95 \times 10^{-5}$ & - & - & - & - \\
\hline $\mathrm{HNO}_{2}$ & $1.75 \times 10^{-4}$ & $7.06 \times 10^{-6}$ & - & - & - \\
\hline
\end{tabular}

Note: solvent $=$ water, temperature $(T)=303 \mathrm{~K}$, static pressure $\left(P_{0}\right)=100 \mathrm{kPa}$, dissolved gas $=$ air, and frequency $(f)=20 \mathrm{kHz}$.

ambient static pressure (i.e., $100 \mathrm{kPa}$ ), and the production of ${ }^{\circ} \mathrm{OH}$ radical decreases as the static pressure approaches to the magnitude of acoustic pressure, that is, $150 \mathrm{kPa}$. The production of ${ }^{\circ} \mathrm{OH}$ radical at $100 \mathrm{kPa}$ is typically 1.5 fold higher than the ${ }^{\circ} \mathrm{OH}$ radical production at $120 \mathrm{kPa}$, while at $150 \mathrm{kPa}$ or higher static pressure no ${ }^{\circ} \mathrm{OH}$ radical formation was seen. This result can be attributed to the temperature peak reached at the moment of collapse of the bubble. At the time of transient collapse, the highest temperature peak (3999 K) was seen when the pressure was $100 \mathrm{kPa}$, while the lowest temperature peak $(\sim 313 \mathrm{~K})$ was observed with elevated static pressure of $300 \mathrm{kPa}$.

3.3. System Operating Temperature. Another important factor that affects the transient cavitation is system temperature. To study the temperature effect on sonochemical process, the numerical simulations were run in the temperature range from 283 to $373 \mathrm{~K}$ (viz. 283, 303, 323, 343, and $373 \mathrm{~K}$ ). The simulation results are depicted in Figure 3. As the temperature in the system increases the formation of oxidizing species due to transient cavitation of bubbles reduces drastically. This could be attributed to the effects of bubble radius as discussed in the earlier section. In this case, vapor bubbles grow with increasing the temperature through the phenomenon of boiling [20]. So, the lower the temperature means the higher the cavitation effects in the system. Table 5 shows that the production of ${ }^{\circ} \mathrm{OH}$ radical is highest with the lowest temperature, that is, at $283 \mathrm{~K}$, while at the boiling point of water no ${ }^{\circ} \mathrm{OH}$ radical formation has been observed. The overall trend of the ${ }^{\circ} \mathrm{OH}$ radical production under various operating temperature is $283 \mathrm{~K}>303 \mathrm{~K}>323 \mathrm{~K}>343 \mathrm{~K}$.

3.4. Type of Dissolved Gas Content. The type of dissolved gas has an impact on bubble nucleation rate as described in the literatures $[15,37]$. The simulation results for four gases are shown in Table 6 and Figure 4. The production of ${ }^{\circ} \mathrm{OH}$ radical as well as $\mathrm{H}_{2} \mathrm{O}_{2}$ is highest for $\mathrm{O}_{2}$ bubble followed by air, $\mathrm{Ar}$, and $\mathrm{N}_{2}$ bubble. Also the generation of $\mathrm{O}_{3}$ per bubble for oxygen bubble is one order of magnitude higher than the $\mathrm{O}_{3}$ generation by air bubble. The radicals by air bubble are formed through the reactions (3)-(22), while (24) and (25) represent the radical formation by $\mathrm{O}_{2}$ bubble [39]. The production of radicals is least with $\mathrm{N}_{2}$ bubble as compared to other gas bubbles. This is due to the scavenging of radicals by $\mathrm{N}_{2}$ molecules through the reactions (3)-(16). Moreover, there is no regeneration of ${ }^{\circ} \mathrm{OH}$ and $\mathrm{O}^{*}$ radicals by $\mathrm{O}_{2}$ when the 
TABLE 4: Simulation summary of sonochemical process under various static pressures $\left(P_{o}\right)$.

\begin{tabular}{|c|c|c|c|c|c|}
\hline & \multicolumn{5}{|c|}{ Conditions at the first collapse of the bubble } \\
\hline & $P_{o}=100 \mathrm{kPa}$ & $P_{o}=120 \mathrm{kPa}$ & $P_{o}=150 \mathrm{kPa}$ & $P_{o}=200 \mathrm{kPa}$ & $P_{o}=300 \mathrm{kPa}$ \\
\hline & $T_{\max }=3999 \mathrm{~K}$ & $T_{\max }=3024 \mathrm{~K}$ & $T_{\max }=977.3 \mathrm{~K}$ & $T_{\max }=353.4 \mathrm{~K}$ & $T_{\max }=312.7 \mathrm{~K}$ \\
\hline & $P_{\max }=696.7 \mathrm{MPa}$ & $P_{\max }=286.3 \mathrm{MPa}$ & $P_{\max }=4.62 \mathrm{MPa}$ & $P_{\max }=416 \mathrm{kPa}$ & $P_{\max }=477 \mathrm{kPa}$ \\
\hline & $V_{\text {turb }}=0.36 \mathrm{~m} / \mathrm{s}$ & $V_{\text {turb }}=0.21 \mathrm{~m} / \mathrm{s}$ & $V_{\text {turb }}=0.07 \mathrm{~m} / \mathrm{s}$ & $V_{\text {turb }}=0.008 \mathrm{~m} / \mathrm{s}$ & $V_{\text {turb }}=0.002 \mathrm{~m} / \mathrm{s}$ \\
\hline & $P_{\mathrm{AW}}=24.04 \mathrm{MPa}$ & $P_{\mathrm{AW}}=5.43 \mathrm{MPa}$ & $P_{\mathrm{AW}}=120 \mathrm{kPa}$ & $P_{\mathrm{AW}}=2 \mathrm{kPa}$ & $P_{\mathrm{AW}}=0.6 \mathrm{kPa}$ \\
\hline & $N_{N_{2}}=1.28 \times 10^{10}$ & $N_{N_{2}}=1.48 \times 10^{10}$ & $N_{\mathrm{N}_{2}}=1.78 \times 10^{10}$ & $N_{\mathrm{N}_{2}}=2.28 \times 10^{10}$ & $N_{\mathrm{N}_{2}}=3.28 \times 10^{10}$ \\
\hline & $N_{\mathrm{O}_{2}}=3.41 \times 10^{9}$ & $N_{\mathrm{O}_{2}}=3.95 \times 10^{9}$ & $N_{\mathrm{O}_{2}}=4.74 \times 10^{9}$ & $N_{\mathrm{O}_{2}}=6.07 \times 10^{9}$ & $N_{\mathrm{O}_{2}}=8.73 \times 10^{9}$ \\
\hline & $N_{\mathrm{W}}=2.91 \times 10^{9}$ & $N_{\mathrm{W}}=1.81 \times 10^{9}$ & $N_{\mathrm{W}}=8.86 \times 10^{8}$ & $N_{\mathrm{W}}=8.19 \times 10^{10}$ & $N_{\mathrm{W}}=3.81 \times 10^{8}$ \\
\hline \multirow{2}{*}{ Species } & \multicolumn{5}{|c|}{ Equilibrium composition of species in the bubble at collapse } \\
\hline & $1 \mathrm{bar}$ & $1.2 \mathrm{bar}$ & $1.5 \mathrm{bar}$ & 2 bar & 3 bar \\
\hline $\mathrm{N}_{2}$ & $6.26 \times 10^{-1}$ & $6.99 \times 10^{-1}$ & $7.60 \times 10^{-1}$ & $7.68 \times 10^{-1}$ & $7.83 \times 10^{-1}$ \\
\hline $\mathrm{O}_{2}$ & $1.28 \times 10^{-1}$ & $1.67 \times 10^{-1}$ & $2.02 \times 10^{-1}$ & $2.04 \times 10^{-1}$ & $2.08 \times 10^{-1}$ \\
\hline $\mathrm{H}_{2} \mathrm{O}$ & $1.41 \times 10^{-2}$ & $7.45 \times 10^{-2}$ & $3.80 \times 10^{-2}$ & $2.80 \times 10^{-2}$ & $9.00 \times 10^{-3}$ \\
\hline $\mathrm{N}$ & $1.56 \times 10^{-5}$ & - & - & - & - \\
\hline $\mathrm{O}$ & $5.95 \times 10^{-3}$ & $9.35 \times 10^{-4}$ & - & - & - \\
\hline $\mathrm{H}$ & $2.83 \times 10^{-4}$ & $4.09 \times 10^{-5}$ & - & - & - \\
\hline $\mathrm{O}_{3}$ & $1.70 \times 10^{-5}$ & $3.71 \times 10^{-6}$ & - & - & - \\
\hline $\mathrm{H}_{2}$ & $2.53 \times 10^{-4}$ & $1.67 \times 10^{-4}$ & - & - & - \\
\hline $\mathrm{OH}$ & $9.51 \times 10^{-3}$ & $6.33 \times 10^{-3}$ & - & - & - \\
\hline $\mathrm{HO}_{2}$ & $5.59 \times 10^{-4}$ & $3.60 \times 10^{-4}$ & - & - & - \\
\hline $\mathrm{H}_{2} \mathrm{O}_{2}$ & $2.00 \times 10^{-5}$ & $2.74 \times 10^{-5}$ & - & - & - \\
\hline NO & $8.47 \times 10^{-2}$ & $4.30 \times 10^{-2}$ & $2.64 \times 10^{-5}$ & - & - \\
\hline $\mathrm{NO}_{2}$ & $1.70 \times 10^{-3}$ & $1.03 \times 10^{-3}$ & $1.09 \times 10^{-5}$ & - & - \\
\hline $\mathrm{N}_{2} \mathrm{O}$ & $3.61 \times 10^{-4}$ & $1.10 \times 10^{-4}$ & - & - & - \\
\hline $\mathrm{NH}$ & $1.70 \times 10^{-6}$ & - & - & - & - \\
\hline $\mathrm{HNO}$ & $5.95 \times 10^{-5}$ & $1.38 \times 10^{-5}$ & - & - & - \\
\hline $\mathrm{HNO}_{2}$ & $1.75 \times 10^{-4}$ & $1.40 \times 10^{-4}$ & - & - & - \\
\hline
\end{tabular}

Note: solvent $=$ water, dissolved gas $=$ air, initial bubble size $\left(R_{0}\right)=5 \mu \mathrm{m}$, temperature $(T)=303 \mathrm{~K}$, and frequency $(f)=20 \mathrm{kHz}$.

bubble contents are $\mathrm{N}_{2}$ gas. So the total number of radicals per bubble in $\mathrm{N}_{2}$ bubbling is always lower than the other gas bubbles. The trend of production of ${ }^{\circ} \mathrm{OH}$ radical per bubble with various gases bubbling is as follows $\mathrm{O}_{2}>\mathrm{Air}>\mathrm{Ar}>\mathrm{N}_{2}$.

$$
\begin{gathered}
\mathrm{N}_{2}+\mathrm{O}^{\bullet} \rightleftarrows \mathrm{N}^{\bullet}+\mathrm{NO} \\
\mathrm{N}_{2}+{ }^{\cdot} \mathrm{OH} \rightleftarrows \mathrm{N}_{2} \mathrm{H}+\mathrm{O}^{\bullet} \\
\mathrm{N}_{2}+{ }^{\circ} \mathrm{OH} \rightleftarrows \mathrm{N}_{2} \mathrm{O}+\mathrm{H}^{\bullet} \\
\mathrm{N}_{2}+{ }^{\bullet} \mathrm{OH} \rightleftarrows \mathrm{NH}+\mathrm{NO} \\
\mathrm{N}_{2}+\mathrm{H}^{\bullet} \rightleftarrows \mathrm{N}_{2} \mathrm{H} \\
\mathrm{N}_{2}+\mathrm{H}^{\bullet} \rightleftarrows \mathrm{NH}+\mathrm{N}^{\bullet} \\
\mathrm{N}_{+}{ }^{\bullet} \mathrm{OH} \rightleftarrows \mathrm{NO}+\mathrm{H}^{\bullet} \\
\mathrm{N}_{2} \mathrm{O}+\mathrm{O}^{\bullet} \rightleftarrows 2 \mathrm{NO}^{\circ} \\
\mathrm{NO}+{ }^{\circ} \mathrm{OH} \rightleftarrows \mathrm{NO}_{2} \\
\mathrm{NH}+{ }^{\circ} \mathrm{OH} \rightleftarrows \mathrm{NH}_{2}+\mathrm{O}^{\bullet}
\end{gathered}
$$

$$
\begin{gathered}
\mathrm{NH}_{2}+\mathrm{O}^{\bullet} \rightleftarrows \mathrm{H}^{\bullet}+\mathrm{HNO} \\
\mathrm{HNO}+\mathrm{O}^{\bullet} \rightleftarrows \mathrm{NH}+\mathrm{O}_{2} \\
\mathrm{HNO}+\mathrm{O}^{\bullet} \rightleftarrows \mathrm{NO}+{ }^{\bullet} \mathrm{OH} \\
\mathrm{HNO}+{ }^{\bullet} \mathrm{OH} \rightleftarrows \mathrm{NO}+\mathrm{H}_{2} \mathrm{O} \\
\mathrm{N}+\mathrm{O}_{2} \rightleftarrows \mathrm{NO}+\mathrm{O}^{\bullet} \\
\mathrm{NO}+\mathrm{O}_{2} \rightleftarrows \mathrm{NO}_{2}+\mathrm{O}^{\bullet} \\
\mathrm{NH}+\mathrm{O}_{2} \rightleftarrows \mathrm{HNO}+\mathrm{O}^{\bullet} \\
\mathrm{NH}+\mathrm{O}_{2} \rightleftarrows \mathrm{NO}^{\bullet} \mathrm{OH}^{\circ} \\
\mathrm{N}_{2}+\mathrm{O}_{2} \rightleftarrows \mathrm{N}_{2} \mathrm{O}+\mathrm{O}^{\bullet} \\
\mathrm{H}^{\bullet}+\mathrm{O}_{2} \rightleftarrows \mathrm{HO}_{2} \\
\mathrm{OH}^{\circ}+\mathrm{O}_{2} \rightleftarrows \mathrm{HO}_{2}^{\bullet}+\mathrm{O}^{\bullet} \\
\mathrm{O}^{\bullet}+\mathrm{O}_{2} \rightarrow \mathrm{O}_{3} \\
2 \mathrm{HO}_{2}^{\bullet} \rightleftarrows \mathrm{H}_{2} \mathrm{O}_{2}+\mathrm{O}_{2}
\end{gathered}
$$


TABLE 5: Simulation summary of system temperature $\left(T_{o}\right)$ dependent sonochemical process.

\begin{tabular}{|c|c|c|c|c|c|}
\hline & \multicolumn{5}{|c|}{ System temperature } \\
\hline & $T=283 \mathrm{~K}$ & $T=303 \mathrm{~K}$ & $T=323 \mathrm{~K}$ & $T=343 \mathrm{~K}$ & $T=373 \mathrm{~K}$ \\
\hline & \multicolumn{5}{|c|}{ Conditions at the first collapse of the bubble } \\
\hline & $T_{\max }=3989 \mathrm{~K}$ & $T_{\max }=3999 \mathrm{~K}$ & $T_{\max }=3733 \mathrm{~K}$ & $T_{\max }=2683 \mathrm{~K}$ & $T_{\max }=811.7 \mathrm{~K}$ \\
\hline & $P_{\max }=681.5 \mathrm{MPa}$ & $P_{\max }=696.7 \mathrm{MPa}$ & $P_{\max }=623.9 \mathrm{MPa}$ & $P_{\max }=175.3 \mathrm{MPa}$ & $P_{\max }=1.79 \mathrm{MPa}$ \\
\hline & $V_{\text {turb }}=0.35 \mathrm{~m} / \mathrm{s}$ & $V_{\text {turb }}=0.36 \mathrm{~m} / \mathrm{s}$ & $V_{\text {turb }}=0.45 \mathrm{~m} / \mathrm{s}$ & $V_{\text {turb }}=1.08 \mathrm{~m} / \mathrm{s}$ & $V_{\text {turb }}=4.63 \mathrm{~m} / \mathrm{s}$ \\
\hline & $P_{\mathrm{AW}}=24.75 \mathrm{MPa}$ & $P_{\mathrm{AW}}=24.04 \mathrm{MPa}$ & $P_{\mathrm{AW}}=21.56 \mathrm{MPa}$ & $P_{\mathrm{AW}}=4.43 \mathrm{MPa}$ & $P_{\mathrm{AW}}=220 \mathrm{kPa}$ \\
\hline & $N_{\mathrm{N}_{2}}=1.38 \times 10^{10}$ & $N_{\mathrm{N}_{2}}=1.28 \times 10^{10}$ & $N_{\mathrm{N}_{2}}=1.21 \times 10^{10}$ & $N_{\mathrm{N}_{2}}=1.13 \times 10^{10}$ & $N_{\mathrm{N}_{2}}=1.04 \times 10^{10}$ \\
\hline & $N_{\mathrm{O}_{2}}=3.66 \times 10^{9}$ & $N_{\mathrm{O}_{2}}=3.41 \times 10^{9}$ & $N_{\mathrm{O}_{2}}=3.20 \times 10^{9}$ & $N_{\mathrm{O}_{2}}=3.02 \times 10^{9}$ & $N_{\mathrm{O}_{2}}=2.77 \times 10^{9}$ \\
\hline & $N_{\mathrm{W}}=7.94 \times 10^{8}$ & $N_{\mathrm{W}}=2.91 \times 10^{9}$ & $N_{\mathrm{W}}=1.23 \times 10^{10}$ & $N_{\mathrm{W}}=8.15 \times 10^{10}$ & $N_{\mathrm{W}}=1.79 \times 10^{12}$ \\
\hline \multirow{2}{*}{ Species } & \multicolumn{5}{|c|}{ Equilibrium composition of species in the bubble at collapse } \\
\hline & $283 \mathrm{~K}$ & $303 \mathrm{~K}$ & $323 \mathrm{~K}$ & $343 \mathrm{~K}$ & $373 \mathrm{~K}$ \\
\hline $\mathrm{N}_{2}$ & $7.07 \times 10^{-1}$ & $6.26 \times 10^{-1}$ & $4.13 \times 10^{-1}$ & $1.16 \times 10^{-1}$ & $6.00 \times 10^{-3}$ \\
\hline $\mathrm{O}_{2}$ & $1.45 \times 10^{-1}$ & $1.28 \times 10^{-1}$ & $8.84 \times 10^{-2}$ & $2.83 \times 10^{-2}$ & $2.00 \times 10^{-3}$ \\
\hline $\mathrm{H}_{2} \mathrm{O}$ & $1.63 \times 10^{-2}$ & $1.41 \times 10^{-2}$ & $1.21 \times 10^{-2}$ & $2.80 \times 10^{-2}$ & $9.93 \times 10^{-1}$ \\
\hline $\mathrm{N}$ & $1.72 \times 10^{-5}$ & $1.56 \times 10^{-5}$ & $3.84 \times 10^{-6}$ & - & - \\
\hline $\mathrm{O}$ & $6.67 \times 10^{-3}$ & $5.95 \times 10^{-3}$ & $2.44 \times 10^{-3}$ & $5.69 \times 10^{-5}$ & - \\
\hline $\mathrm{H}$ & $3.21 \times 10^{-4}$ & $2.83 \times 10^{-4}$ & $1.06 \times 10^{-4}$ & $2.57 \times 10^{-6}$ & - \\
\hline $\mathrm{O}_{3}$ & $1.89 \times 10^{-5}$ & $1.70 \times 10^{-5}$ & $8.38 \times 10^{-6}$ & $2.28 \times 10^{-7}$ & - \\
\hline $\mathrm{H}_{2}$ & $2.91 \times 10^{-4}$ & $2.53 \times 10^{-4}$ & $1.30 \times 10^{-4}$ & $2.29 \times 10^{-5}$ & - \\
\hline $\mathrm{OH}$ & $1.08 \times 10^{-2}$ & $9.51 \times 10^{-3}$ & $5.27 \times 10^{-3}$ & $8.08 \times 10^{-4}$ & - \\
\hline $\mathrm{HO}_{2}$ & $6.31 \times 10^{-4}$ & $5.59 \times 10^{-4}$ & $3.25 \times 10^{-4}$ & $4.22 \times 10^{-5}$ & - \\
\hline $\mathrm{H}_{2} \mathrm{O}_{2}$ & $2.28 \times 10^{-5}$ & $2.00 \times 10^{-5}$ & $1.36 \times 10^{-5}$ & $4.60 \times 10^{-6}$ & - \\
\hline $\mathrm{NO}$ & $9.51 \times 10^{-2}$ & $8.47 \times 10^{-2}$ & $4.72 \times 10^{-2}$ & $4.57 \times 10^{-3}$ & - \\
\hline $\mathrm{NO}_{2}$ & $1.90 \times 10^{-3}$ & $1.70 \times 10^{-3}$ & $1.04 \times 10^{-3}$ & $1.11 \times 10^{-4}$ & - \\
\hline $\mathrm{N}_{2} \mathrm{O}$ & $4.01 \times 10^{-4}$ & $3.61 \times 10^{-4}$ & $1.88 \times 10^{-4}$ & $8.69 \times 10^{-6}$ & - \\
\hline $\mathrm{NH}$ & $1.89 \times 10^{-6}$ & $1.70 \times 10^{-6}$ & - & - & - \\
\hline HNO & $6.67 \times 10^{-5}$ & $5.95 \times 10^{-5}$ & $2.74 \times 10^{-5}$ & $9.69 \times 10^{-7}$ & - \\
\hline $\mathrm{HNO}_{2}$ & $1.96 \times 10^{-4}$ & $1.75 \times 10^{-4}$ & $1.12 \times 10^{-4}$ & $1.76 \times 10^{-5}$ & - \\
\hline
\end{tabular}

Note: solvent $=$ water, dissolved gas $=$ air, initial bubble size $\left(R_{0}\right)=5 \mu \mathrm{m}$, static pressure $\left(P_{0}\right)=100 \mathrm{kPa}$, and frequency $(f)=20 \mathrm{kHz}$.

3.5. Type of Solvent or Cavitation Medium. The solvent or cavitation medium is another important factor that affects directly on the sonochemical process. In order to assess the suitability of solvent for cavitation, we have chosen three solvents with different physicochemical properties, namely, water, toluene, and n-hexane, as shown in Table 2. To address this issue, we have presented the numerical solution with various solvent as cavitation medium in Figure 5 and Table 7 , which lists the temperature and pressure peak reached at the moment of collapse with various equilibrium compositions of species. The number of ${ }^{\bullet} \mathrm{OH}$ radical production is highest when water is used as cavitation medium. This can be attributed to the lower surface tension and higher vapor pressure of the organic solvent. The production of ${ }^{\circ} \mathrm{OH}$ radical in water is typically two orders of magnitude higher than that in toluene. So, due to the low intensity of bubble collapse, organic solvents are not able to generate sufficient numbers of radical in-situ for sonochemical reactions.

\section{Conclusions}

The lower is the system temperature the higher is the cavitation effects, that is, when the system temperature is moderately low the effect of cavitation is more. In this present study, the radical formation due to cavitation is highest when the system temperature is $283 \mathrm{~K}$. So, the system with low operating temperature and cavitation medium contents with small initial bubble radius is always preferable for sonochemical reactions since this type of sonochemical reaction systems are able to generate large amount of highly oxidizing species. Due to the high vapor pressure and low surface tension, organic solvents cannot produce large amount of radicals in the reaction medium; thus, they are not suitable for sonochemical reactions. However, they could be good solvents for extraction or other processes using ultrasound. Moreover, depending on the process requirement one can choose the system with different gas bubbling and aqueous or organic solvents for conducting experiments.

\section{Nomenclature}

$C_{V, i}:$ Heat capacity at constant volume, $\mathrm{J}$ $\mathrm{kg}^{-1} \mathrm{~K}^{-1}$

$c_{\mathrm{L}}$ : Velocity of sound in liquid medium, $\mathrm{m} \mathrm{s}^{-1}$

$c_{\mathrm{W}}$ : Velocity of sound in water, $\mathrm{m} \mathrm{s}^{-1}$ 
TABLE 6: Effect of dissolved gas content on sonochemical process.

\begin{tabular}{|c|c|c|c|c|}
\hline & \multicolumn{4}{|c|}{ Conditions at the first collapse of the bubble } \\
\hline & Air bubble & Nitrogen bubble & Oxygen bubble & Argon bubble \\
\hline & $T_{\max }=3999 \mathrm{~K}$ & $T_{\max }=4379 \mathrm{~K}$ & $T_{\max }=4155 \mathrm{~K}$ & $T_{\max }=4551 \mathrm{~K}$ \\
\hline & $P_{\max }=696.7 \mathrm{MPa}$ & $P_{\max }=772.3 \mathrm{MPa}$ & $P_{\max }=758.2 \mathrm{MPa}$ & $P_{\max }=786.6 \mathrm{MPa}$ \\
\hline & $V_{\text {turb }}=0.36 \mathrm{~m} / \mathrm{s}$ & $V_{\text {turb }}=0.37 \mathrm{~m} / \mathrm{s}$ & $V_{\text {turb }}=0.37 \mathrm{~m} / \mathrm{s}$ & $V_{\text {turb }}=0.37 \mathrm{~m} / \mathrm{s}$ \\
\hline & $P_{\mathrm{AW}}=24.04 \mathrm{MPa}$ & $P_{\mathrm{AW}}=28.25 \mathrm{MPa}$ & $P_{\mathrm{AW}}=30.78 \mathrm{MPa}$ & $P_{\mathrm{AW}}=27.28 \mathrm{MPa}$ \\
\hline & $N_{\mathrm{N}_{2}}=1.28 \times 10^{10}$ & $N_{\mathrm{N}_{2}}=1.63 \times 10^{10}$ & $N_{\mathrm{O}_{2}}=1.63 \times 10^{10}$ & $N_{\mathrm{Ar}}=1.63 \times 10^{10}$ \\
\hline & $N_{\mathrm{O}_{2}}=3.41 \times 10^{9}$ & $N_{\mathrm{W}}=3.88 \times 10^{9}$ & $N_{\mathrm{W}}=3.88 \times 10^{9}$ & $N_{\mathrm{W}}=2.54 \times 10^{9}$ \\
\hline & $N_{\mathrm{W}}=2.91 \times 10^{9}$ & & & \\
\hline \multirow{2}{*}{ Species } & \multicolumn{4}{|c|}{ Equilibrium composition of species in the bubble at collapse } \\
\hline & Air bubble & Nitrogen bubble & Oxygen bubble & Argon bubble \\
\hline $\mathrm{N}_{2}$ & $6.26 \times 10^{-1}$ & $8.05 \times 10^{-1}$ & - & - \\
\hline $\mathrm{O}_{2}$ & $1.28 \times 10^{-1}$ & $2.80 \times 10^{-4}$ & $7.93 \times 10^{-1}$ & $1.09 \times 10^{-3}$ \\
\hline $\mathrm{Ar}$ & - & - & - & $8.65 \times 10^{-1}$ \\
\hline $\mathrm{H}_{2} \mathrm{O}$ & $1.41 \times 10^{-2}$ & $9.69 \times 10^{-3}$ & $1.13 \times 10^{-2}$ & $9.21 \times 10^{-3}$ \\
\hline $\mathrm{N}$ & $1.56 \times 10^{-5}$ & $5.85 \times 10^{-5}$ & - & - \\
\hline $\mathrm{O}$ & $5.95 \times 10^{-3}$ & $5.06 \times 10^{-4}$ & $1.87 \times 10^{-2}$ & $1.34 \times 10^{-3}$ \\
\hline $\mathrm{H}$ & $2.83 \times 10^{-4}$ & $2.48 \times 10^{-3}$ & $2.21 \times 10^{-4}$ & $2.59 \times 10^{-3}$ \\
\hline $\mathrm{N}_{3}$ & - & $1.45 \times 10^{-6}$ & - & - \\
\hline $\mathrm{O}_{3}$ & $1.70 \times 10^{-5}$ & - & $3.28 \times 10^{-4}$ & - \\
\hline $\mathrm{H}_{2}$ & $2.53 \times 10^{-4}$ & $6.73 \times 10^{-3}$ & $1.03 \times 10^{-4}$ & $4.31 \times 10^{-3}$ \\
\hline $\mathrm{OH}$ & $9.51 \times 10^{-3}$ & $2.50 \times 10^{-3}$ & $1.57 \times 10^{-2}$ & $4.09 \times 10^{-3}$ \\
\hline $\mathrm{HO}_{2}$ & $5.59 \times 10^{-4}$ & $6.77 \times 10^{-6}$ & $2.34 \times 10^{-3}$ & $2.07 \times 10^{-5}$ \\
\hline $\mathrm{H}_{2} \mathrm{O}_{2}$ & $2.00 \times 10^{-5}$ & $8.86 \times 10^{-7}$ & $4.75 \times 10^{-5}$ & $1.79 \times 10^{-6}$ \\
\hline $\mathrm{NO}$ & $8.47 \times 10^{-2}$ & $5.65 \times 10^{-3}$ & - & - \\
\hline $\mathrm{NO}_{2}$ & $1.70 \times 10^{-3}$ & $4.93 \times 10^{-6}$ & - & - \\
\hline $\mathrm{N}_{2} \mathrm{O}$ & $3.61 \times 10^{-4}$ & $3.02 \times 10^{-5}$ & - & - \\
\hline $\mathrm{NH}$ & $1.70 \times 10^{-6}$ & $2.68 \times 10^{-5}$ & - & - \\
\hline $\mathrm{NH}_{2}$ & - & $2.42 \times 10^{-5}$ & - & - \\
\hline $\mathrm{NH}_{3}$ & - & $1.78 \times 10^{-5}$ & - & - \\
\hline $\mathrm{HNO}$ & $5.95 \times 10^{-5}$ & $2.25 \times 10^{-5}$ & - & - \\
\hline $\mathrm{HNO}_{2}$ & $1.75 \times 10^{-4}$ & $2.16 \times 10^{-6}$ & - & - \\
\hline
\end{tabular}

Note: solvent $=$ water, initial bubble size $\left(R_{0}\right)=5 \mu \mathrm{m}$, temperature $(T)=303 \mathrm{~K}$, static pressure $\left(P_{0}\right)=100 \mathrm{kPa}$, and frequency $(f)=20 \mathrm{kHz}$. $\mathrm{O}_{2}>$ air $>\operatorname{Ar}>$ $\mathrm{N}_{2}$.

$c_{\mathrm{T}}: \quad$ Velocity of sound in toluene, $\mathrm{m} \mathrm{s}^{-1}$

$c_{\mathrm{H}}$ : Velocity of sound in n-hexane, $\mathrm{m} \mathrm{s}^{-1}$

$D_{\mathrm{w}}$ : Diffusion coefficient of solvent vapor, $\mathrm{m}^{2}$ $\mathrm{s}^{-1}$

$f: \quad$ Frequency of ultrasound wave, $\mathrm{Hz}$

$f_{i}$ : Translational and rotational degrees of freedom

$h$ : Van der Waal's hard core radius, $m$

$I_{\text {diff,w }}$ : Instantaneous diffusive penetration depth for water molecules

$k$ : Boltzmann constant, $\mathrm{J} \mathrm{K}^{-1}$

$N_{\mathrm{W}}$ : Number of water molecules trapped in the bubble

$N_{\mathrm{N}_{2}}$ : Number of $\mathrm{N}_{2}$ molecules in the bubble

$N_{\mathrm{O}_{2}}$ : Number of oxygen molecules in the bubble

$N_{\mathrm{T}}$ : Number of toluene molecules in the bubble

$N_{\mathrm{H}}$ : Number of $\mathrm{n}$-hexane molecules in the bubble
$N_{\text {Ar }}$ : Number of Ar molecules in the bubble

$N_{\text {tot }}$ : Total number of molecules (gas + vapor) in the bubble

$P_{o}: \quad$ Static pressure in the liquid medium, $\mathrm{Pa}$

$P_{\max }$ : Pressure peak reached in the bubble at the time of first collapse, $\mathrm{Pa}$

$P_{\mathrm{AW}}$ : Pressure amplitude of the acoustic wave generated by the cavitation bubble, $\mathrm{Pa}$

Q: $\quad$ Heat conducted across bubble wall, $\mathrm{J} \mathrm{s}^{-1}$

$R: \quad$ Radius of the bubble, $m$

$R_{o}$ : Initial radius of the cavitation bubble, $\mathrm{m}$

$d R / d t$ : Bubble wall velocity, $\mathrm{m} \mathrm{s}^{-1}$

$t: \quad$ Time, $s$

$T: \quad$ Temperature of the bubble contents, $\mathrm{K}$

$T_{o}$ : Ambient (or bulk liquid medium) temperature, $\mathrm{K}$

$T_{\max }$ : Temperature peak reached in the bubble at the time of first collapse, $\mathrm{K}$ 
TABLE 7: Simulation summary of sonochemical process with different solvent as cavitation medium.

\begin{tabular}{|c|c|c|c|}
\hline & \multicolumn{3}{|c|}{ Conditions at the first collapse of the bubble } \\
\hline & $\mathrm{H}_{2} \mathrm{O}_{2}$ & $\mathrm{C}_{6} \mathrm{H}_{5}-\mathrm{CH}_{3}$ & $\mathrm{C}_{6} \mathrm{H}_{12}$ \\
\hline & $T_{\max }=3179 \mathrm{~K}$ & $T_{\max }=4835 \mathrm{~K}$ & $T_{\max }=1151 \mathrm{~K}$ \\
\hline & $P_{\max }=355 \mathrm{MPa}$ & $P_{\max }=961.7 \mathrm{MPa}$ & $P_{\max }=44.55 \mathrm{MPa}$ \\
\hline & $V_{\text {turb }}=0.25 \mathrm{~m} / \mathrm{s}$ & $V_{\text {turb }}=0.15 \mathrm{~m} / \mathrm{s}$ & $V_{\text {turb }}=0.005 \mathrm{~m} / \mathrm{s}$ \\
\hline & $P_{\mathrm{AW}}=12.61 \mathrm{MPa}$ & $P_{\mathrm{AW}}=30.16 \mathrm{MPa}$ & $P_{\mathrm{AW}}=188 \mathrm{kPa}$ \\
\hline & $N_{\mathrm{N}_{2}}=1.31 \times 10^{10}$ & $N_{\mathrm{N}_{2}}=1.13 \times 10^{9}$ & $N_{\mathrm{N}_{2}}=1.07 \times 10^{10}$ \\
\hline & $N_{\mathrm{O}_{2}}=3.47 \times 10^{9}$ & $N_{\mathrm{O}_{2}}=2.99 \times 10^{8}$ & $N_{\mathrm{O}_{2}}=2.85 \times 10^{9}$ \\
\hline & $N_{\mathrm{W}}=1.21 \times 10^{9}$ & $N_{\mathrm{T}}=4.02 \times 10^{3}$ & $N_{\mathrm{H}}=6.05 \times 10^{10}$ \\
\hline \multirow[t]{2}{*}{ Species } & \multicolumn{3}{|c|}{$\begin{array}{l}\text { Equilibrium composition of species in the bubble at } \\
\text { collapse }\end{array}$} \\
\hline & $\mathrm{H}_{2} \mathrm{O}_{2}$ & $\mathrm{C}_{6} \mathrm{H}_{5}-\mathrm{CH}_{3}$ & $\mathrm{C}_{6} \mathrm{H}_{12}$ \\
\hline $\mathrm{N}_{2}$ & $7.09 \times 10^{-1}$ & $7.17 \times 10^{-1}$ & $1.40 \times 10^{-1}$ \\
\hline $\mathrm{O}_{2}$ & $1.66 \times 10^{-1}$ & $1.26 \times 10^{-1}$ & - \\
\hline $\mathrm{H}_{2} \mathrm{O}$ & $5.37 \times 10^{-2}$ & - & $6.28 \times 10^{-2}$ \\
\hline $\mathrm{N}$ & - & $1.92 \times 10^{-4}$ & - \\
\hline $\mathrm{O}$ & $1.38 \times 10^{-3}$ & $2.06 \times 10^{-2}$ & - \\
\hline $\mathrm{H}$ & $5.90 \times 10^{-5}$ & $1.51 \times 10^{-6}$ & - \\
\hline $\mathrm{N}_{3}$ & - & $3.86 \times 10^{-6}$ & - \\
\hline $\mathrm{O}_{3}$ & $5.44 \times 10^{-6}$ & $3.84 \times 10^{-5}$ & - \\
\hline $\mathrm{H}_{2}$ & $1.77 \times 10^{-4}$ & - & $8.98 \times 10^{-1}$ \\
\hline $\mathrm{OH}$ & $6.96 \times 10^{-3}$ & $1.95 \times 10^{-5}$ & - \\
\hline $\mathrm{HO}_{2}$ & $4.10 \times 10^{-4}$ & $1.04 \times 10^{-6}$ & - \\
\hline $\mathrm{H}_{2} \mathrm{O}_{2}$ & $2.68 \times 10^{-5}$ & - & - \\
\hline NO & $5.14 \times 10^{-2}$ & $1.42 \times 10^{-1}$ & - \\
\hline $\mathrm{NO}_{2}$ & $1.23 \times 10^{-3}$ & $2.29 \times 10^{-3}$ & - \\
\hline $\mathrm{NO}_{3}$ & - & $1.66 \times 10^{-6}$ & - \\
\hline $\mathrm{N}_{2} \mathrm{O}$ & $1.49 \times 10^{-4}$ & $7.48 \times 10^{-4}$ & - \\
\hline $\mathrm{N}_{2} \mathrm{O}_{3}$ & - & $1.15 \times 10^{-6}$ & - \\
\hline $\mathrm{HNO}$ & $1.91 \times 10^{-5}$ & - & - \\
\hline $\mathrm{HNO}_{2}$ & $1.57 \times 10^{-4}$ & - & - \\
\hline $\mathrm{CO}$ & - & $7.10 \times 10^{-6}$ & $1.18 \times 10^{-2}$ \\
\hline $\mathrm{CO}_{2}$ & - & $1.26 \times 10^{-5}$ & $7.02 \times 10^{-4}$ \\
\hline $\mathrm{NH}_{3}$ & - & - & $9.90 \times 10^{-3}$ \\
\hline $\mathrm{HCN}$ & - & - & $1.48 \times 10^{-5}$ \\
\hline $\mathrm{CH}_{4}$ & - & - & 2.37 \\
\hline $\mathrm{C}_{2} \mathrm{H}_{4}$ & - & - & $1.11 \times 10^{-4}$ \\
\hline $\mathrm{C}_{2} \mathrm{H}_{6}$ & - & - & $4.09 \times 10^{-3}$ \\
\hline
\end{tabular}

Note: dissolved gas $=$ air, initial bubble size $\left(R_{0}\right)=5 \mu \mathrm{m}$, temperature $(T)=$ $303 \mathrm{~K}$, static pressure $\left(P_{0}\right)=100 \mathrm{kPa}$, and frequency $(f)=35 \mathrm{kHz}$.

$V_{\text {turb }}$ : Average velocity of the microturbulence in the medium generated by ultrasound and cavitation in the medium (estimated at $1 \mathrm{~mm}$ distance from bubble center), $\mathrm{m} \mathrm{s}^{-1}$

$\rho_{\mathrm{L}}: \quad$ Density of the liquid, $\mathrm{kg} \mathrm{m}^{-3}$

$v$ : Kinematic viscosity of liquid, $\mathrm{m}^{2} \mathrm{~s}^{-1}$

$\sigma: \quad$ Surface tension of liquid, $\mathrm{N} \mathrm{m}^{-1}$

$\kappa$ : Thermal conductivity of bubble contents, $\mathrm{W} \mathrm{m}^{-1} \mathrm{~K}^{-1}$

$\lambda$ : Thermal diffusivity of bubble contents, $\mathrm{m}^{2}$ $s^{-1}$ $\theta$ : Characteristic vibrational temperature(s) of the species, $\mathrm{K}$.

\section{Conflict of Interests}

The authors of the paper do not have any direct financial relation that might lead to a conflict of interest for any of the authors.

\section{References}

[1] J. O. Hirschfelder, C. F. Curtiss, and R. B. Bird, Molecular Theory of Gases and Liquids, John Wiley \& Sons, New York, NY, USA, 1954.

[2] E. U. Condon and H. Odishaw, Handbook of Physics, McGrawHill, New York, NY, USA, 1958.

[3] R. C. Reid, J. M. Prausnitz, and B. E. Poling, Properties of Gases and Liquids, McGraw-Hill, New York, NY, USA, 1987.

[4] H. Xu, B. W. Zeiger, and K. S. Suslick, "Sonochemical synthesis of nanomaterials," Chemical Society Reviews, vol. 42, pp. 25552567, 2013.

[5] J. H. Bang and K. S. Suslick, "Applications of ultrasound to the synthesis of nanostructured materials," Advanced Materials, vol. 22, no. 10, pp. 1039-1059, 2010.

[6] S. Kanmuri and V. S. Moholkar, "Mechanistic aspects of sonochemical copolymerization of butyl acrylate and methyl methacrylate," Polymer, vol. 51, no. 14, pp. 3249-3261, 2010.

[7] M. Sivakumar, A. Gedanken, W. Zhong et al., "Nanophase formation of strontium hexaferrite fine powder by the sonochemical method using $\mathrm{Fe}(\mathrm{CO})_{5}$," Journal of Magnetism and Magnetic Materials, vol. 268, no. 1-2, pp. 95-104, 2004.

[8] P. R. Gogate and G. S. Bhosale, "Comparison of effectiveness of acoustic and hydrodynamic cavitation in combined treatment schemes for degradation of dye wastewaters," Chemical Engineering and Processing: Process Intensificationdoi, 2013.

[9] S. Chakma and V. S. Moholkar, "Physical mechanism of sonofenton process," AIChE Journal, 2013.

[10] J. B. Bhasarkar, S. Chakma, and V. S. Moholkar, "Mechanistic features of oxidative desulfurization using sono-fentonperacetic acid (Ultrasound/Fe ${ }^{2+}-\mathrm{CH}_{3} \mathrm{COOH}-\mathrm{H}_{2} \mathrm{O}_{2}$ ) system," Industrial \& Engineering Chemistry Research, vol. 52, no. 26, pp. 9038-9047, 2013.

[11] P. Braeutigam, M. Franke, R. J. Schneider, A. Lehmann, A. Stolle, and B. Ondruschka, "Degradation of carbamazepine in environmentally relevant concentrations in water by Hydrodynam ic-Acoustic-Cavitation (HAC)," Water Research, vol. 46, no. 7, pp. 2469-2477, 2012.

[12] J. Madhavan, P. S. S. Kumar, S. Anandan, M. Zhou, F. Grieser, and M. Ashokkumar, "Ultrasound assisted photocatalytic degradation of diclofenac in an aqueous environment," Chemosphere, vol. 80, no. 7, pp. 747-752, 2010.

[13] P. A. Parkar, H. A. Choudhary, and V. S. Moholkar, "Mechanistic and kinetic investigations in ultrasound assisted acid catalyzed biodiesel synthesis," Chemical Engineering Journal, vol. 187, pp. 248-260, 2012.

[14] H. A. Choudhury, S. Chakma, and V. S. Moholkar, "Mechanistic insight into sonochemical biodiesel synthesis using heterogeneous base catalyst," Ultrasonics Sonochemistry, 2013.

[15] J. Rooze, E. V. Rebrov, J. C. Schouten, and J. T. F. Keurentjes, "Dissolved gas and ultrasonic cavitation-a review," Ultrasonics Sonochemistry, vol. 20, pp. 1-11, 2013. 
[16] K. D. Bhatte, S.-I. Fujita, M. Arai, A. B. Pandit, and B. M. Bhanage, "Ultrasound assisted additive free synthesis of nanocrystalline zinc oxide," Ultrasonics Sonochemistry, vol. 18, no. 1, pp. 54-58, 2011.

[17] K. S. Suslick, M. M. Mdleleni, and J. T. Ries, "Chemistry induced by hydrodynamic cavitation," Journal of the American Chemical Society, vol. 119, no. 39, pp. 9303-9304, 1997.

[18] J. S. Krishnan, P. Dwivedi, and V. S. Moholkar, "Numerical investigation into the chemistry induced by hydrodynamic cavitation," Industrial and Engineering Chemistry Research, vol. 45, no. 4, pp. 1493-1504, 2006.

[19] T. G. Leight, The Acoustic Bubble, Academic Press, London, UK, 1995.

[20] Y. T. Shah, A. B. Pandit, and V. S. Moholkar, Cavitation Reaction Engineering, Kluwer Academic/Plenum, New York, NY, USA, 1999.

[21] K. S. Suslick, “Sonochemistry," Science, vol. 247, no. 4949, pp. 1439-1445, 1990.

[22] T. Sivasankar and V. S. Moholkar, "Mechanistic approach to intensification of sonochemical degradation of phenol," Chemical Engineering Journal, vol. 149, no. 1-3, pp. 57-69, 2009.

[23] R. Andreozzi, V. Caprio, A. Insola, and R. Marotta, "Advanced oxidation processes (AOP) for water purification and recovery," Catalysis Today, vol. 53, no. 1, pp. 51-59, 1999.

[24] R. E. Apfel, “Acoustic cavitation inception," Ultrasonics, vol. 22, no. 4, pp. 167-173, 1984.

[25] C. Gong and D. P. Hart, "Ultrasound induced cavitation and sonochemical yields," Journal of the Acoustical Society of America, vol. 104, no. 5, pp. 2675-2682, 1998.

[26] K. S. Suslick, Y. Didenko, M. M. Fang et al., "Acoustic cavitation and its chemical consequences," Philosophical Transactions of the Royal Society A, vol. 357, no. 1751, pp. 335-353, 1999.

[27] P. R. Gogate and A. B. Pandit, "A review of imperative technologies for wastewater treatment II: hybrid methods," Advances in Environmental Research, vol. 8, no. 3-4, pp. 553-597, 2004.

[28] R. Toegel, B. Gompf, R. Pecha, and D. Lohse, "Does water vapor prevent upscaling sonoluminescence?” Physical Review Letters, vol. 85, no. 15, pp. 3165-3168, 2000.

[29] B. D. Storey and A. J. Szeri, "Water vapour, sonoluminescence and sono chemistry," Proceedings of the Royal Society A, vol. 456, no. 1999, pp. 1685-1709, 2000.

[30] J. B. Keller and M. Miksis, "Bubble oscillations of large amplitude," Journal of the Acoustical Society of America, vol. 68, no. 2, pp. 628-633, 1980.

[31] R. B. Bird, W. E. Stewart, and E. N. Lightfoot, Lightfoot, Transport Phenomena, John Wiley \& Sons, New York, NY, USA, 2nd edition, 2001.

[32] W. H. Press, S. A. Teukolsky, B. P. Flannery, and W. T. Vetterling, Numerical Recipes, Cambridge University Press, New York, NY, USA, 2nd edition, 1992.

[33] G. Eriksson, "Thermodynamic studies of high temperature equilibria-XII: SOLGAMIX, a computer program for calculation of equilibrium composition in multiphase systems," Chemica scripta, vol. 8, pp. 100-103, 1975.

[34] S. Grossmann, S. Hilgenfeldt, M. Zomack, and D. Lohse, "Sound radiation of 3-MHz driven gas bubbles," Journal of the Acoustical Society of America, vol. 102, no. 2, pp. 1223-1230, 1997.

[35] V. S. Moholkar and M. M. C. G. Warmoeskerken, "Integrated approach to optimization of an ultrasonic processor," AIChE Journal, vol. 49, no. 11, pp. 2918-2932, 2003.
[36] FACTSAGE, http://www.factsage.com/.

[37] P. Kumar and V. S. Moholkar, "Numerical assessment of hydrodynamic cavitation reactors using organic solvents," Industrial and Engineering Chemistry Research, vol. 50, no. 8, pp. 47694775, 2011.

[38] S. Chakma and V. S. Moholkar, "Mechanistic features of ultrasonic desorption of aromatic pollutants," Chemical Engineering Journal, vol. 175, no. 1, pp. 356-367, 2011.

[39] A. Prosperetti and A. Lezzi, "Bubble Dynamics in a compressible liquid. part 1. first order theory," Journal of Fluid Mechanics, vol. 168 , pp. $457-478,1986$. 

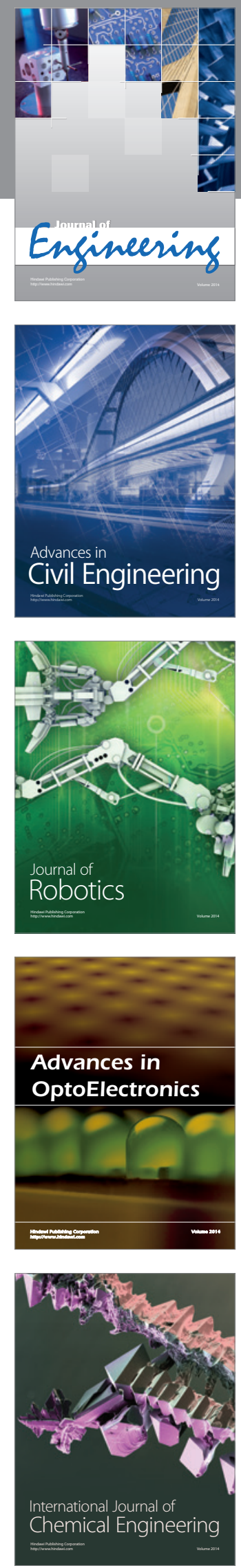

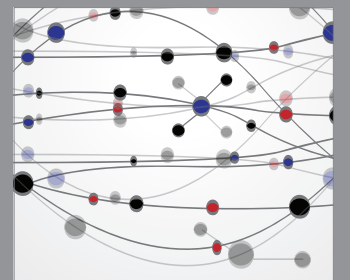

The Scientific World Journal
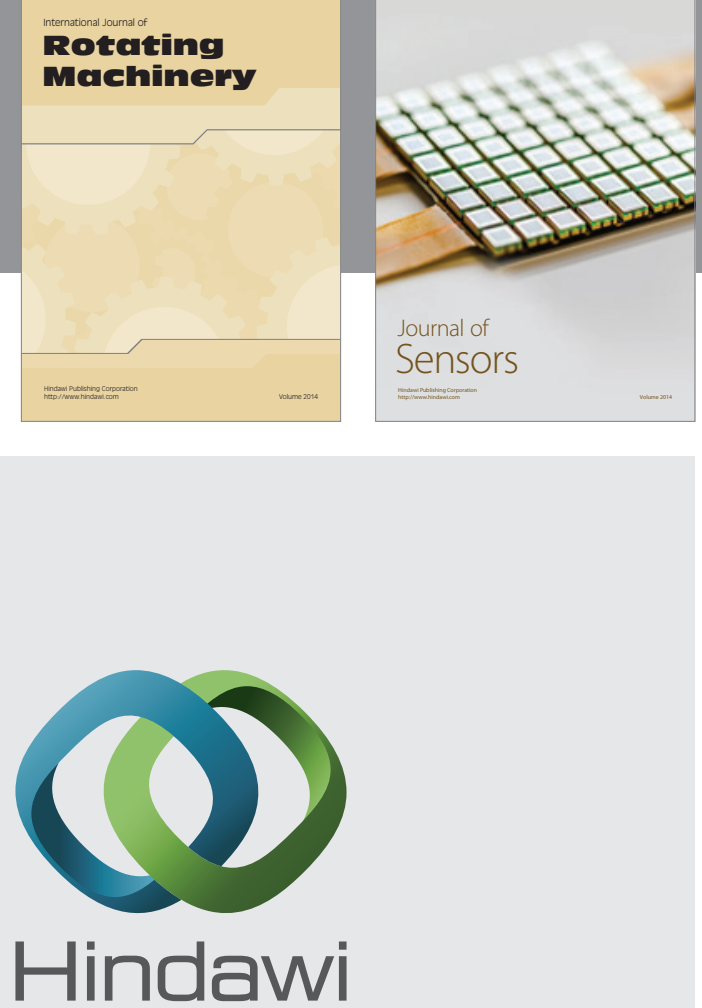

Submit your manuscripts at http://www.hindawi.com
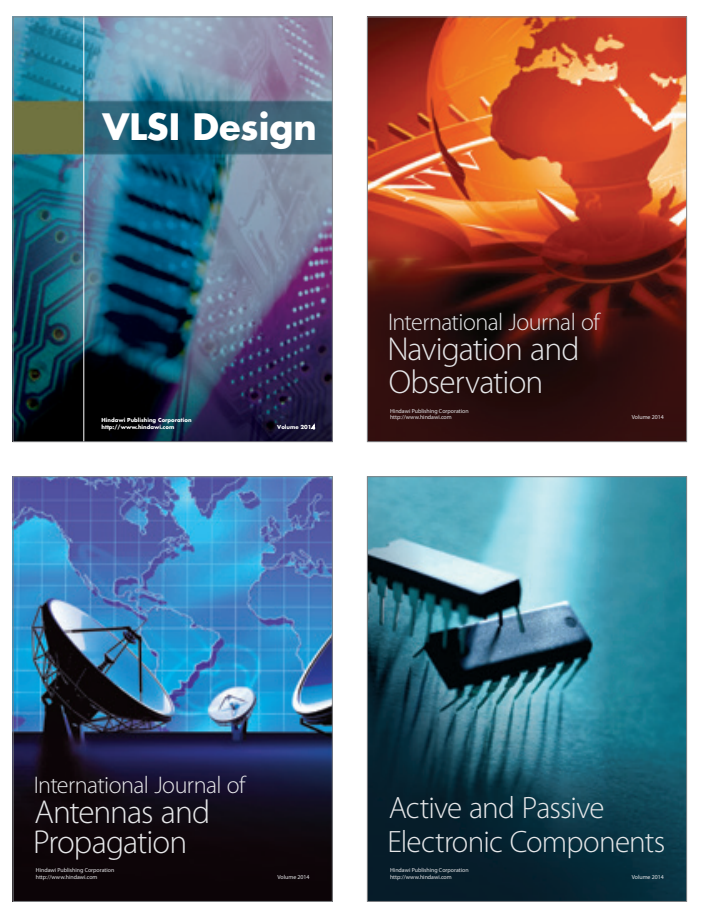
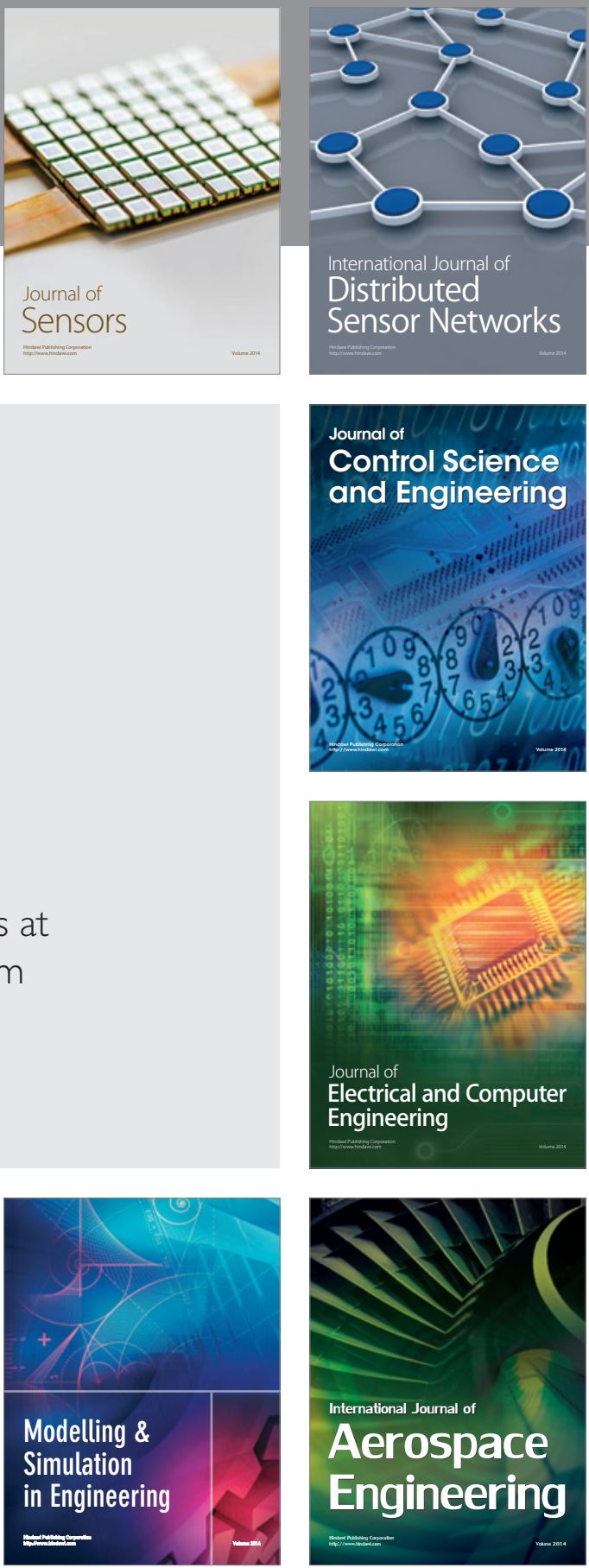

Journal of

Control Science

and Engineering
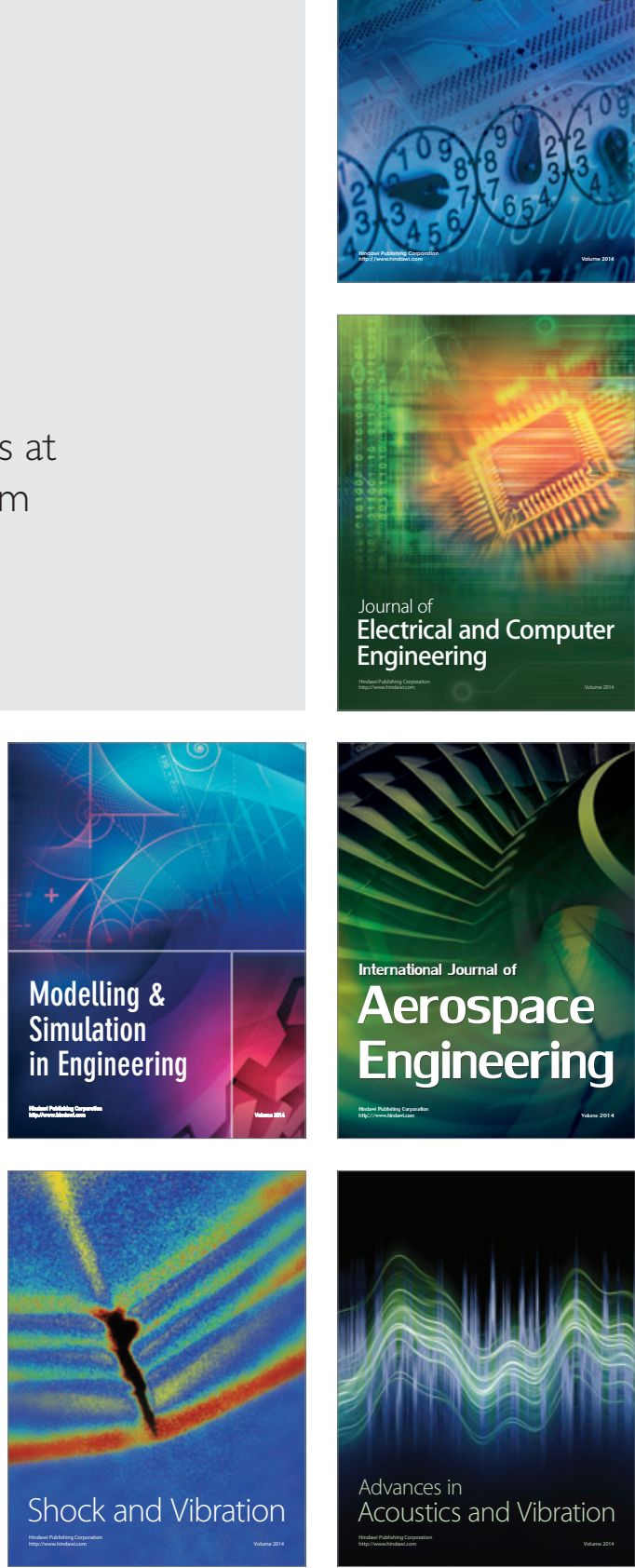